UNIVERSITY OF MINNESOTA

ST. ANTHONY FALLS HYDRAULIC LABORATORY

LORENZ G. STRAUB, Director

Technical Paper No. 32, Series B

\title{
Pulsation of Ventilated Cavities
}

by

C. S. SONG

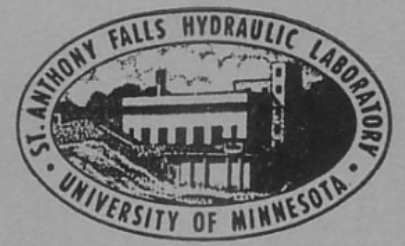

February 1961

Minneapolis, Minnesota 


\section{ERRATA SHEET}

Please note the following corrections:

Equation (5) on page 8 should read:

$$
\text { K. E. }=(l / 2) \rho \int_{r_{0}}^{R_{0}}\left(\frac{s}{2 \pi r}\right)^{2} \cdot 2 \pi r d r=\frac{\rho s^{2}}{L \pi} \ln \frac{R_{0}}{r_{0}}
$$

The equation in the middle of page 10 should read:

$$
\sigma=\frac{4 \theta}{\pi \sqrt{\ell}}[1+0(1 / \ell)]
$$

July 5, 1961 
UNIVERSITY OF MINNESOTA

ST. ANTHONY FALLS HYDRAULIC LABORATORY

LORENZ G. STRAUB, Director

Technical Paper No. 32, Series B

\section{Pulsation of Ventilated Cavities}

by

C. S. SONG

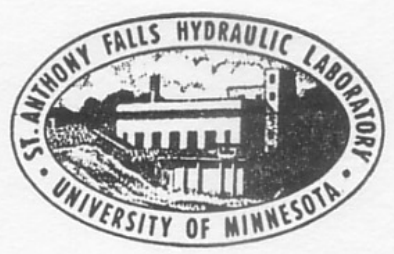

February 1961

Minneapolis, Minnesota 
Reproduction in whole or in part is permitted

for any purpose of the United States Government 


$$
\underline{A} \underline{B} \underline{S} \underline{T} \underline{R} \underline{A} \underline{C} \underline{T}
$$

The problem of pulsating supercavities under artificial ventilation is analyticallytreated as a resonance problemof a two-dimensional gas-liquid system using a linearized method. A simple kinematical consideration and a dynamical model of the flow lead to solutions for frequency and amplitude of pulsations. The criteria of pulsation is givenin terms of a formula relating $\sigma_{\mathrm{v}}$ and $\sigma$. Maximum air carrying capacities of pulsating cavities are also estimated. Most of the formulas involve an undetermined constant which must be estimated by using experimental data. The analytical results are compared with the experimental data obtained at the St. Anthony Falls Hydraulic Laboratory, and in general, good agreement is obtained.

It is found that pulsation is possible only for a two-dimensional cavity or a cavity in which a substantial portion of the span can be regarded as two-dimensional. The existence of a free surface is also essential to pulsation. The strong effect of the free surface suggests that pulsation may become an important problem in the open sea only when submergence is relatively small. 
Abstract ......................... . . . $i i i$ List of Illustrations. . . . . . . . . . . . . . . . v v List of Symbols....................... vi



II. MECHANISM OF PULSATING CAVITIES. . . . . . . . . . . 2

III. KINEMATI CS OF PULSATING CAVITIES .............. 3

IV. THE MATHEMATICAL MODEL AND ITS SOLUTION FOR PULSATING CAVITIES • 5

A. Mathematical Model . . . . . . . . . . . 5

B. Natural Frequency of the Gas-Liquid System ....... 6

C. Cavitation Number of Pulsating Cavities. . . . . . . 9 9

D. Amplitude of Pulsation ............. 12

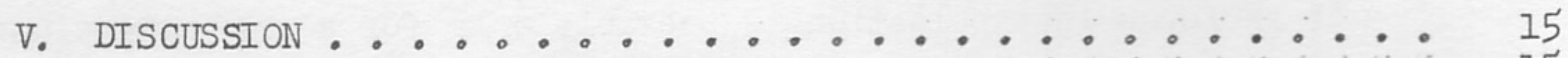

A. Inception of Pulsation .......................... 15

B. Effect of Air Supply Rate.............. 16

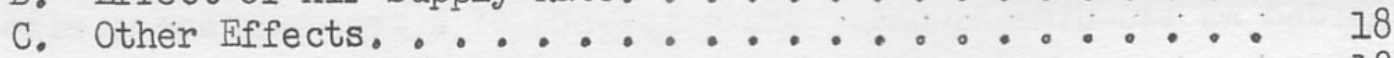

1. Boundary Conditions. ............ 18

2. Cavity Shape .........: : 19

3. Compressibility and Viscosity of Water : : . : 19

4. Gravitation............. 20



VI. CONCLUSIONS。 . . . . . . . . . . . . . 20

List of References ........................ 21

Figures 1 through $11 \ldots . . . \ldots 24$ 


\section{$\underline{L} \underline{I} \underline{S} \underline{T} \quad \underline{O} \underline{F} \quad \underline{I} \underline{L} \underline{L} \underline{U} \underline{S} \underline{T} \underline{R} \underline{A} \underline{\underline{T}} \underline{I} \underline{O} \underline{N} \underline{S}$}

Figure

1 Kinematics of First-Stage Pulsating Cavity ........ 25

2 Trajectories of Liquid Particles Leaving a Solid Boundary. . 26

3 Experimental Data Showing Dimensionless Frequency as a Function of Stage. ............... 27

4 Pulsating Cavity Model ................. 28

5 Frequency as a Function of Cavity Length . . . . . . 29

6 Cavitation Number for Each Pulsating Stage as a Function of Initial Cavitation Number ............ 30

$7 \quad$ Cavitation Number for Each Pulsating Stage as a Function of Initial Cavitation Number Plotted on Logarithmic

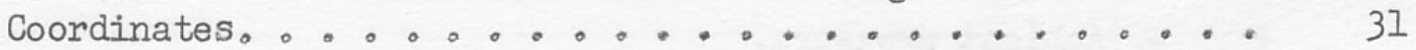

8 Amplitude of Pressure Pulsations in Cavities ....... 32

9 Relative Amplitude of Pressure Pulsations in Water Outside

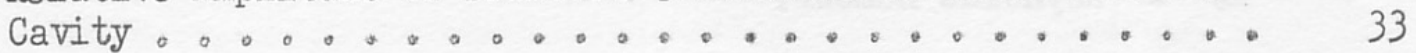

10 Photographs of Pulsating Cavities............. 34

11 Air Supply Rate for Pulsating Cavities ......... 35 


$$
\underline{I} \underline{I} \underline{S} \quad \underline{O} \underline{F} \quad \underline{S} \underline{Y} \underline{M} \underline{B} \underline{O} \underline{L} \underline{S}
$$

B - Width of test body.

$C_{W}$ - Air supply coefficient。

E - Total energy。

F - Function。

$f$ - Frequency of pulsation.

$\mathrm{K}, \mathrm{K}^{\prime}$ - Constants.

L - Length of test body。

$\ell$ - Cavity length。

n - Number pf pulsation stages。

$\mathrm{P}_{\mathrm{a}}$ - Average partial cavity pressure due to air or gas.

$P_{c}$ - Cavity pressure。

$\mathrm{P}_{\mathrm{V}}$ - Partial cavity pressure due to water vapor.

$\mathrm{P}_{\infty}$ - Ambient pressure.

q - Radial velocity。

Re - Reynolds number。

$R_{0}$ - Radius of external boundary.

$r$ - Radial distance。

$r_{0}$ - Radius of circle filled with gas.

$r_{1}$ - Radial distance at equilibrium condition.

S - Steady cavity area。

$S_{0}^{\prime}$ - Part of the steady cavity area filled with air or gas.

$s$ - Change of cavity area.

$s_{i}$ - General coordinates。

$T$ - Period of pulsation.

$U$ - Undisturbed free stream velocity。

$U_{c}$ - Velocity at cavity walls 


$$
\begin{aligned}
& W_{A}-\text { Weight rate of air supply. } \\
& W-\text { Jet width. } \\
& \beta-\text { A parameter. } \\
& \Delta P-\text { Amplitude of pressure pulsation. } \\
& \theta-\text { Half wedge angle. } \\
& K-\text { Gas constant. } \\
& \rho-\text { Density of liquid. } \\
& P_{a}-\text { Density of air. } \\
& \sigma-\frac{P}{}-P_{c} \\
& \sigma_{v}-\frac{P_{\infty}-P_{v}}{l / 2 \rho U^{2}}=\text { cavitation number based on vapor pressure. }
\end{aligned}
$$




\section{I。 INTRODUCTION}

In recent years considerable interest has been given to simulating natural supercavities by ventilation. Simulation has wide practical application such as elimination of cavitation damage, reduction of cavitation noise, and reduction of skin friction, to name a few. The economy and success of this type of work hinge upon two problems: the amount of gas required to produce a desired cavity and the circumstances under which it is possible to maintain a stable cavity。

It has been shown by many investigators that it is possible to increase the cavity pressure by air injection, resulting in a decrease in cavitation number and an increase in cavity size. However, a smooth relationship between gas supply rate and cavitation number does not necessarily always exist. When air supplyrate reaches some value, depending upon circumstances, abnormal conditions occur and, from this point on, an increase in air supply rate is not necessarily followed by an increase in cavity pressure or increase in cavity size. To date, the following three sources of the anomalies are known:

1) hollow vortex tubes; this phenomenon is associated with a towing tank experiment where a gravitationalfield is perpendicular to the direction of flow. It was found by cox and Clayden $[1,2]^{*}$ that the circulation induced by the head difference between two cavity walls creates two hollow vortex tubes at the tail of the cavity resulting in sharp increase in the gas flow rate.

2) tunnel blockage; this phenomenon is associated with a closed tunnel test。 Recently Lang and Daybell [3] reported thatwhen the cavitation number reached that of tunnel blockage the tumel was choked and further reduction of the cavitation number was impossible。

3) pulsating cavity; this is a phenomenon associated with a free surface. Pulsating cavities were first found by

\footnotetext{
* Numbers in brackets refer to the list of References on p.22.
} 
Silberman and Song [4] while studying ventilated cavities in a free jet tunnel. A similar phenomenon was also observed by Wetzel and Schiebe [5] in a towing tank。 There were two free surfaces in the former case, but there was only one free surface in the latter case.

The mechanism of the first two phenomena is well known and needs no further discussion here. There is a discussion of the possible mechanism of the pulsating cavities in a paper by Cuthbert [6]. However, quantitative analysis of the phenomena is still lacking. The purpose of the present paper is, therefore, to present an analytical treatment of the problem together with some data to support the result.

This research has been supported by the Office of Naval Research of The U. S。 Department of the Navy under Contract Nonr 710(24), Task NR 062-052。 The entire project was under the direction of Dr. Lorenz G. Straub, Director of the St. Anthony Falls Hydraulic Laboratory. Professor Edward Silberman has been the leader of the project and critically reviewed the present work。 Stimulating discussions with Messrs. J。 M。 Wetzel and $F_{0} R_{0}$ Schiebe are acknowledged. The manuscript was prepared for printing by Marjorie Summers under the general supervision of Loyal Johnson.

\section{MECHANISM OF PULSATING CAVITIES}

Itwas reported in Reference [4] that the cavity pressure, and hence the cavity size, may be increased by ventilating a given cavity. The higher the air supply rate the higher the cavity pressure. This relationship holds until a critical point is reached. Further increase in air supply rate beyond the critical point fails to increase the cavity pressure, but rather, will cause the cavity pressure to fluctuate. High speed motion pictures as reported in Reference [4] revealed that the cavity walls of the pulsating cavities consist of traveling waves. (Figure 10 shows typical views of pulsating cavities。)

It was found that pulsation occurs only when air is introduced ine to the cavity. It was also found that the phenomenon is independent of the air supply system. The size and length of the air pipe, the location and distribution of the air entrance to the cavity, or any other possible change 
in the air supply system did not seem to affect the pulsation. The pulsating cavities were classified by stages according to the number of waves appearing on the cavities. It was revealed that for each stage of pulsation there exists a unique relationship between the average cavitation number of the cavity and the cavitation number based upon vapor pressure. That is, for each stage of pulsation there is a relationship between the five variables: $P_{\infty}, P_{c}$,

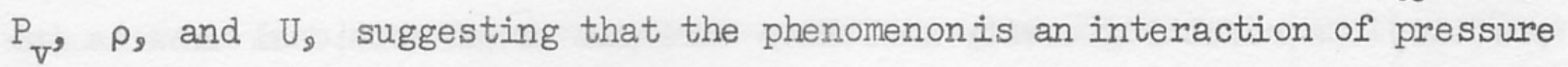
and momentum forces。

The experimental facts stated abovelead to the suggestion that pulsation is a resonance phenomenon of the gas-liquid (cavity-jet) system. The traveling surface wave on the cavity walls causes the cavity volume to change periodically, hence changing the cavity pressure periodically。 The pulsating cavity pressure sets the bounding liquidinto radial motion, creating new disturbances at the body and new surface waves. In order for the pulsation to be self sustaining, the frequency of the volume change due to the moving surface waves must be equal to the natural frequency of the gas-liquid system. If this idea is correct, then the problem is to find the frequency of the volume pulsation due to the surface wave and the natural frequency of the gasliquid system. The first part of the problem can be solved by considering the kinematics of the pulsation, whereas the second part of the problem requires a dynamical consideration.

\section{III。 KINEMATICS OF PULSATING CAVITIES}

Consider a steady cavity profile as shownin Fig。 I(a)。 The cavity is assumed to be so long that the length of the solid body may be neglected, and the cavity is assumed to start from the leading edge。 Consider, next, a movingwave of constant amplitude and wave length as shown in Fig。 l(b). For simplicity, first consider a single-stage pulsation of which the wave length is equal to the average cavity length $\ell$. Superimposition of the wave profiles on the steady cavity profile will create a new profile which changes with time。

Since the boundary condition at the leading edge requires that the cavity width be constant throughout a period of pulsation, the wave profiles to be superimposed on the steady cavity profile do not allow a finite amplitude 
at the leading edge. This means that waves with growing amplitudes along the direction of flow are necessary. Wave profiles sketched in Fig. $I(c)$ meet this requirement. Superimposition of (c) on (a) results in new profiles as shown in Fig. I(d). These predicted cavity shapes resemble the actual cavity shapes as shown by motion pictures in Fig. 8 of Reference [4]。 Because of the variable amplitude of the waves to be superimposed on the steady cavity profile, the resulting cavity will have variable cross-sectional area as indicated in Fig. I(d). The period of the area pulsation of the cavity is seen to be equal to the period of the traveling wave. This leads to the following formula:

$$
\mathrm{T}=\ell / \mathrm{c} \text { or } \mathrm{f} \ell / \mathrm{c}=1
$$

where $T=$ the period of the traveling wave,

$f=$ the frequency of cavity pulsation $=I / T$,

$\ell=$ the average cavity length, and

$c=$ the apparent speed of the wave.

Similar argument for n-stage pulsating cavities will lead to the following formula:

$$
\mathrm{T}=\ell / \mathrm{nc} \text { or } \mathrm{f} \ell / \mathrm{c}=\mathrm{n}
$$

Attention is now directed to the apparent speed of the surface wave. Consider a small mass of liquid leaving the solid boundary at point $A$ as indicated in Fig。 2(a)。 If pressure were constant in the cavity, the trajectory of the particle would describe a solid line $\overparen{A B C}$. When pressure in the cavity exceeds that of the steady cavity, the corresponding pressure gradient normal to the direction of the flow will be smaller and, therefore, the curvature of the trajectory will be smaller, and vice versa. General shapes of pressure fluctuation curves are sketched in $\mathrm{F}_{i g}$. $2(\mathrm{~b})$ by using $U_{c} t$ as the horizontal scale. Here $U_{c}$ is the speed of liquid particles on a steady cavity wall and $t$ is time. It is readily seen that if the particle leaving $A$ follows the upper pressure curve, then the trajectory of the particle $\mathrm{AB}^{\prime} \mathrm{C}^{\prime}$ will lie outside of line $\overparen{A B C}$. On the other hand, if the particle leaving $A$ follows the lower pressure curve, then the trajectory of the particle $\mathrm{AB}^{\prime \prime} \mathrm{C}^{\prime \prime}$ will lie inside of line $\overparen{A B C}$. All other trajectories will lie between $\widehat{A B}^{8} \mathrm{C}^{8}$ and $\mathrm{AB}^{\prime \prime} \mathrm{C}^{\prime \prime}$. Line $\mathrm{AB}^{\circ} \mathrm{C}^{\mathrm{n}}$ is the envelope of the pulsating cavity as sketched 
in Fig. $I(d)$ and line $\overparen{A B^{\prime \prime}} C^{\prime \prime}$ is the trace of the neck appearing in the sketches. Since the liquid particle is moving with average speed $U_{c}$, the average apparent speed of the surface wave will also be equal to $U_{C}$. The apparent average wave speeds were measured by means of motion pictures for different stages of pulsations and in all cases confirmed the present statement. The apparent wave speed appears to change within a cycle of pulsation and any measurement not covering a complete cycle may give different results. This is why a statement was made in Reference [4] that for first- and second-stage cavities the speed is less than $U_{c^{*}}$ New measurements covering a cycle of pulsation disproved the statement.

Equation (la) may now be replaced by

$$
\mathrm{f} \ell / \mathrm{U}_{\mathrm{c}}=\mathrm{n}
$$

To check the validity of Eq. (Ib) the data reported in Reference [4] and some newdata were analysed and the results are shown in Fig. 3. Since the data shown in Fig. 3 cover different test bodies of variable shapes and dimensions over a wide range of flow conditions, $\mathrm{Eq},(\mathrm{lb})$ is believed to be universally applicable。

It is also noteworthy that, according to Fig. I(d), the length of an $n$-stage pulsating cavity changes periodically from $(I-I / 4 n) \ell$ to $(I+I / 4 n) \ell$ 。 The apparent wave speed, or the speed of the cavity tail, changes approximately from $U_{c} / 2$ to $2 U_{c}$ during a period of motion.

The remaining part of the problemis to find the resonance frequency of the gas-liquid system. Small pulsation of a spherical cavity was solved by previous investigators and is well summarized in a paper by Devin [7]. Since the present problem is a two-dimensional one, a similar analysis will be carried out for the case of resonating cylindrical gas bubbles in liquid.

\section{IV。 THE MATHEMATICAL MODEL AND ITS SOLUTION FOR PULSATING CAVITIES}

A. Mathematical Model

Consider a two-dimensional steady cavity of unit width in a finite free jet as shown in Fig。 $4(a)$. The pressure difference $P_{\infty}-P_{c}$ is in balance with the centrifugal force due to the motion of liquid along curved stream lines. Because of this equilibrium, it may be assumed as a first 
approximation that the natural frequency of the dynamic system is equal to that of the static system shown in Fig. 4(b). Of course, under the static condition a real cavity will not take a form as shown in Fig. 4(b), but will rather be a circle. Fortunately, the natural frequency of the volume pulsation of a gas cavity is nearly independent of its shape [8], and the cavity in Fig。 4(b) may be replacedby a circular cavity of equal area without causing too much error.

In reality, a cavity is filled not only with air but also with water vapor and water particles. Since the water within the cavity plays no part in pressure change, the part of the area occupied by water must be left out of consideration. Furthermore, the role of water vapor in volume pulsation is not completely understood. It is perhaps a reasonable assumption if vapor pressure is treated as a constant and left out of consideration. The model (b) can now be replaced by model (c) in Fig. 4; here, the total cavity area $S$ has been reduced to $S_{0}^{8}$. by subtracting theinternal area occupied by water and water vapor. Finally, the two walls of the free jet will be replaced by a circle of diameter $R_{0}$ as shown in Fig. 2(d). The problem is now reduced to that of calculating the natural frequency of the cylindrical air-water system。

B. Natural Frequency of the Gas-Liquid System

Let us now apply a small change of the cavity area $s$ to the equilibrium condition. This will destroy the equilibrium and will set up a flow. If the space outside of the external boundary is large the pressure on the external boundary will remain essentially constant. Furthermore, if the applied area change is such that the resulting area is a circle, the flow will be radial.

Lagrange's equation of motion in a general coordinate system for an irrotational motion is [9]

$$
\frac{d}{d t}\left(\frac{\partial E}{\partial s_{i}}\right)-\frac{\partial E}{\partial s_{i}}=Q_{i}
$$

where $s_{i}=$ general coordinates,

$\mathrm{E}=$ kinetic energy plus potential energy, and

$Q_{i}=$ external force. 
Here it is convenient to take the change of cavity area, s, as the generalized coordinate. The potential energy of the bubble with reference to the equilibrium condition is

$$
\text { P. } E_{0}=\int_{S_{0}^{3}}^{S_{0}^{1}+s} p d s
$$

where $S_{0}^{\prime}$ is the area of the gas bubble at equilibrium condition. Assuming that the flow of the gas is isentropic so that

$$
p\left(S_{0}^{\prime}+s\right)^{K}=P_{a} S_{0}^{\prime K}
$$

where $K=a$ gas constant, and

$\mathrm{P}_{\mathrm{a}}=$ average partial pressure due to gas,

the potential energy of the gas takes the following form:

$$
P_{0} E_{0}=P_{a} s-\frac{K P_{a}}{2 S_{0}^{1}} s^{2}+0\left(s^{3}\right)
$$

Assuming incompressible flow the potential energy of the liquid is equal to zero.

Since the density of the gas is so small compared with that of the liquid, the kinetic energy of the gas may be neglected. Therefore, it is necessary to calculate the kinetic energy of the bounding liquid only. By considering the continuity requirements, we have

$$
s=\pi\left(r^{2}-r_{1}^{2}\right)
$$

where $r$ is the radial distance of a particle at any instant, and $r_{1}$ is the corresponding distance at equilibrium condition. Differentiating the above equation with respect to time and noting that $\mathrm{dr} / \mathrm{dt}$ is the velocity q, we get

$$
q=s / 2 \pi r
$$


The kinetic energy is

$$
\text { K. E. }=1 / 2 \rho \int_{r_{0}}^{R_{0}}\left(\frac{\dot{s}}{2 \pi r}\right)^{2} \cdot 2 \pi r d r=\frac{\rho s^{2}}{4 r} \ln \frac{R_{0}}{r_{0}}
$$

Retaining the first two terms only in Eq. (3) the total energy of the system is

$$
E=\frac{\rho s^{2}}{4 \pi} \ln \frac{R_{0}}{r_{0}}+P_{a} s-\frac{K P_{a}}{2 s_{0}^{1}} s^{2}
$$

The only external force acting on the systemis the constant pressure $\mathrm{P}_{\mathrm{a}}$ acting on the external boundary of the liquid. Consequently, it can be shown that

$$
Q_{i}=-P_{a}
$$

Finally, the substitution of (6) and (7) into (2) yields

$$
\left(\frac{\rho}{2 \pi} \ln \frac{R_{0}}{r_{0}}\right) s+\frac{K P_{a}}{s_{0}^{\prime}} s=0
$$

Equation (8) is the equation of a vibrating spring without damping and excitation. The frequency of the vibration is

$$
f=\frac{1}{2 \pi} \sqrt{\frac{2 \pi K P_{a}}{\rho S_{0}^{\prime} \ln \frac{R_{0}}{r_{0}}}}
$$

Since the part of the cavity space filled with water is not known, we may write

$$
S_{0}^{\prime}=K S
$$

where $S$ is the total cavity area at equilibrium condition, and $K$ is a constant for a given cavity. 
Using $K=1.4, \mathrm{Eq}$. (9) takes the following form:

$$
f=0.473 \sqrt{\frac{P_{a}}{K \rho S \ln \frac{R_{0}}{r_{0}}}}
$$

Since both $S$ and $r_{0}$ are functions of the cavity length $\ell$ and $R_{0}$ is a function of the jet width, w, we may write

$$
\frac{f}{\sqrt{P_{a} / P}}=F(\ell, w)
$$

The frequency data for pulsating cavities produced by normal flat plates and circular cylinders obtained in the free jet are shownin Fig. 5. The functional relationship between $\mathrm{f} / \sqrt{\mathrm{P}_{\mathrm{a}} / \mathrm{p}}$ and cavity length as indicated by Eq。( $9 \mathrm{~b}$ ) is thus clearly demonstrated by the experimental data.

From (9a) it is expected that the frequency of the pulsation is also weakly affected by the jet width. Frequency should decrease as the jet widthincreases and should become zero as $R_{0} \rightarrow \infty$. This means that pulsation is possible onlyin a finite jet with free boundary unless the liquid is compressible. It is also natural to expect pulsation to be easier to attain in a narrower jet than in a wider jet. In fact, it was observed in the towing tank experiments at the St. Anthony Falls Hydraulic Laboratory under a separate contract that ventilated cavities are more likely to pulsate at low submergence than at higher submergence. For deep submergence the hollow vortex tubes take the place of the pulsation. To show the effect of the jet width on the frequency of pulsation, existing data [4] and some newdata are plotted in Fig. 5(c). Although there is some scatter the trendis clearly demonstrated.

\section{Cavitation Number of Pulsating Cavities}

By virtue of Bernoulli's equation and the definition of cavitation number, Eq. (Ib) may be written as

$$
\mathrm{f} \ell / \mathrm{U}=\sqrt[n]{1+\sigma}
$$

where $U$ is the undisturbed stream velocity and $\sigma$ is the cavitation number defined as 


$$
\sigma=\frac{P_{\infty}-P_{c}}{1 / 2 \rho U^{2}}
$$

The combination of $(9 a)$ and (10) leads to the following formula:

$$
\frac{P_{a}}{1 / 2 \rho U^{2}}=8.93 \mathrm{Kn}^{2}(1+\sigma) \frac{S}{\ell^{2}} \ln \frac{R_{0}}{r_{0}}
$$

Here the cavity area $S$ and the cavity length $\ell$ will have to be calculated by one of the known methods for steady cavities. For the purpose of illustration, for example, Wu's [10] solution for thin wedges in an infinite fluid may be taken. It was shown by wu that

$$
S=\theta \ell^{3 / 2}
$$

and

$$
\sigma=\frac{4 \theta}{\sqrt[n]{\ell}}[1+O(I / \ell)]
$$

where $\theta$ is the half vertex angle.

For a long cavity we may thus write

$$
\frac{S}{\ell^{2}}=\frac{\pi}{4} \sigma
$$

Using the above condition Eq. (1I) may be written as

$$
\frac{P_{a}}{1 / 2 \rho U^{2}}=7.01 K n^{2}(I+\sigma) \sigma \ln \frac{R_{0}}{r_{0}}
$$

By definition it follows that

$$
\sigma_{v}=\sigma+7.01 \mathrm{Kn}^{2}(1+\sigma) \sigma \ln \frac{\mathrm{R}_{0}}{r_{0}}
$$




$$
\sigma_{\mathrm{v}}=\left(1+7.01 \mathrm{Kn}^{2} \ln \frac{\mathrm{R}_{\mathrm{o}}}{\mathrm{r}_{\mathrm{o}}}\right) \sigma+\left(7.01 \mathrm{Kn}^{2} \ln \frac{\mathrm{R}_{0}}{\mathrm{r}_{0}}\right) \sigma^{2}
$$

where $\sigma_{v}=\frac{P_{\infty}-P_{V}}{1 / 2 \rho U^{2}}$.

The empirical formula given in the previous report [4], which was intended to be used for all stages except the first stage, is

$$
\sigma_{v}=\frac{n^{2}}{0.29} \sigma
$$

The strong resemblance of Eq. (12) and the empirical equation is noted. The last term in Eq. (12) may be considered as the correction factor for the empirical formula (13).

The factor In $\frac{R_{0}}{r_{0}}$ is presumably a function of jet width and cavity size. However, the exact evaluation of this factoris not to be attempted in this report. For most of the tests performedin the 10-in. jet, this value is believed to range from near unity to 2.3. To make the first term of (12) agree with (13) for $n \rightarrow \infty$

$$
K \ln \frac{R_{0}}{r_{0}}=0.491
$$

This means the value of $K$ is

$$
0.2<K<0.5
$$

indicating a large part of the cavity is filled with water and water vapor [see equations following Eq. (9)]. By (14) the equation for cavitation number becomes

$$
\sigma_{v}=\left(1+3.45 n^{2}\right) \sigma+3.45 n^{2} \sigma^{2}
$$

The data given in the previous report [4] are reproduced in Fig. 6. Solid lines are for Eq. (16) and dotted lines are for the empirical formula (13). 
The data of Fig. 6 for full span normal flat plates have been replotted in Fig. 7 on log-log paper. This plotting shows that Eq. (16) does not fit the data too well at the highest cavitation numbers for a small number of stages. A new empirical formula can be written from Fig. 7 that fits the lower stage cavities well. It is

$$
\sigma_{V}=10\left(1+n^{2}\right) \sigma^{3 / 2}
$$

and is plotted as broken lines in Fig. 7.

On the whole, however, the semi-empirical Eq. (16) fits the available data well for all stages of pulsationas is apparent from Figs. 6 and 7 . It should be recalled, however, that the present theory is based on the calculated cavity behind a thin wedge; the relation between $s$ and $\ell$ so obtained may or may not be applicable to the bodies represented in Fig. 6 .

\section{Amplitude of Pulsation}

So far, computations in this section of the paper have been based on the average air pressure in the cavity, $P_{a}$. The true air pressure fluctuates, however, and varies between the limits $P_{a} \pm \frac{\Delta P_{a}}{2}$. To estimate the amplitude of pressure pulsation, reference will be made to the sketches of Fig. 1. It may be observed that the main source of the cavity area change has been attributed to the assumption that the wave to be superimposed on a steady cavity has zero amplitude near the leading edge and increasing amplitude downstream. The maximum area change of the first-stage cavity is given by

$$
s_{\max }=\int_{0}^{\ell} y d x=\beta s_{0}^{\prime}
$$

of the upper wave of Fig。 $I$ (c) where $\beta$ is an unknown parameter presumably a function of cavity size and air supply rate. In the case of a multi-stage cavity, the change of cavity area may be assumed to occur mainly within the first wave length as may be deduced by examination of Fig. 10. This concept leads to the following expression for a cavity at any stage $\mathrm{n}$ : 


$$
s_{\max }=\frac{\beta s_{0}^{\prime}}{n}
$$

By the adiabatic law of perfect gas, it can be calculated that

$$
P_{a_{\max }}\left(s_{0}^{\prime}-s_{\max }\right)^{K}=P_{a_{\min }}\left(s_{0}^{\prime}+s_{\max }\right)^{K}=P_{a}\left(s_{0}^{\prime}\right)^{K}
$$

or

$$
\frac{\Delta P_{a}}{P_{a}}=\left(\frac{n}{n-\beta}\right)^{K}-\left(\frac{n}{n+\beta}\right)^{K}
$$

where

$$
\Delta P_{a}=P_{a_{\max }}-P_{a_{\min }}
$$

Some of the existing (unpublished) and new amplitude data are analysed and shown in Fig. 8. The dimensionless amplitude $\Delta \mathrm{P}_{\mathrm{a}} / \mathrm{P}_{\mathrm{a}}$ is plotted against the air supply coefficient $C_{W}$ (defined in the next section) for a number of different stages. Solid lines are from $\mathrm{Eq}$. (18) with $\beta=0.18$. It is seen that with this empirical value of $\beta$ the experimental data can be made to approach the theoretical values as $C_{W}$ increases for each stage.

The relative amplitude of pressure pulsation outside of a cavity is to be examined next. The linearized velocity potential, $\phi$, in the liquid region is, from Eq. (4),

$$
\phi=\frac{s}{2 \pi} \ln r / R_{0}
$$

The solution of $\mathrm{Eq}$. (8) satisfying the condition $\mathrm{s}(0)=0$ is

$$
s=s_{\max } \sin 2 \pi f t
$$

The Bermoulli equation for unsteady, incompressible, irrotational flows with constant external conditions is

$$
q^{2} / 2+P / p-\partial \phi / \partial t=\text { constant }
$$


Solving Eqs. (19), (20), and (21) simultaneously,

$$
\begin{aligned}
\frac{P-P_{a}}{\rho} & =-I / 2 f^{2} s_{\max }{ }^{2}\left(l / r^{2}-l / R_{0}^{2}\right) \cos ^{2} 2 \pi f t \\
& +2 \pi f^{2} s_{\max }\left(\ln \frac{R_{o}}{r}\right) \sin 2 \pi f t
\end{aligned}
$$

The maximum amplitude of the pulsation occurs when $\sin (2 \pi f t)= \pm I$ and may be written in dimensionless form as

$$
\frac{\Delta P}{4 \pi \rho f^{2} s_{\max }}=\ln \frac{R_{0}}{r}
$$

where $\triangle P=P_{\max }-P_{\min }$ in the liquid outside the cavity.

Within the cavity, the adiabatic law, Eq. (18), may be written approximately

$$
\frac{\Delta P_{a}}{P_{a}} \approx \frac{2 K \beta}{n}
$$

or

$$
s_{\text {max }} \approx \frac{\Delta P_{a}}{2 K P_{a}} s_{0}^{\prime}
$$

Combination of Eqs. (9) and (24) then leads to

$$
f^{2} s_{\max } \approx \frac{\Delta P_{a}}{4 \pi \rho \ln \frac{R_{0}}{r_{0}}}
$$

Using Eq. (25), Eq. (23) is reduced to

$$
\frac{\Delta \mathrm{P}}{\Delta \mathrm{P}_{\mathrm{a}}} \approx \frac{\ln \frac{\mathrm{R}_{0}}{\mathrm{r}}}{\ln \frac{\mathrm{R}_{0}}{\mathrm{r}_{0}}}
$$


It is readily checked that (26) satisfies the following boundary conditions:

(1) $\Delta P=\Delta P_{a}$ at $r=r_{0}$

(2) $\Delta P=0$ at $r=R_{0}$

Equation (26) is plotted in $F_{i g} .9(a)$ as a family of curves with $R_{0} / r_{0}$ as a parameter.

To study the amplitude variation in the liquid outside of cavities a pressure transducer was installed flush with the tunnel wall side by side with an existing pressure transducer which measuredinternal cavity pressure. Pressure amplitudes of first-stage pulsations were measured both inside and outside the cavity for a $3 / 4 \mathrm{in}$. long wedge with 27 degree vertex angle in various size jets. The relative pressure amplitude is plotted against the relative distance of the pressure transducerfrom the center line of the cavity in Fig. 9(b) for several ratios of jet width, $w$, to cavity length $\ell$. Contourlines for constant $w / \ell$ are drawn tentatively. Since $R_{0}$ is related to $w$ and $r$ o to $\ell$, the contour lines in Fig. $9(b)$ should be related to those in Fig. $9(a)$. Since, however, the exact $R_{0}$ vs $w$ and $r_{0} v s ~ l$ relationships are not known, Fig. 9(b) confirms only the general trend of Eq. (26).

\section{DISCUSSION}

\section{A. Inception of Pulsation}

For a given flow condition, $U_{c}$ and $n$ are constant. This means, referring to $\mathrm{Eq}$. (Ib), the frequency of pulsation is a function of cavity length only. This frequency must also be equal to the natural frequency of the system given by Eq. (9) in order for pulsation to exist. In other words, the cavity length must be constant across the span of the cavity--the cavity must be a two-dimensional cavity. Practically, a pulsating cavity need not be perfectly uniformacross the span; it is sufficient if the cavity is nearly uniform over part of the span. In the case of a two-dimensional cavity the whole cavity pulsates severely as is illustrated in the photograph of Fig. 10(a). For a finite aspect ratio foil, a cavity may pulsate only at a central part of the cavity where the cavity length is nearly uniform. A photograph obtained in the towing tank and shown on the left in Fig. 10(b) illustrates this point. It is a known fact that a full span test body pulsates 
more easily and more strongly than a similar half span test body [4]. Another striking example is shown on the right in Fig. 10(b) where a foil with end plates is seen to have a more uniform cavity than the foil without plates and, consequently, pulsates more easily and strongly.

Finally, to have a pulsation, the cavity size and the reentrant jet must adjust themselves so that the amount of water in the cavity, pressure in the cavity, and the cavitylength are compatiblewith the resonance conditions. It was pointedout in Reference [4] that there was an experimental upper limit to each of the $\sigma_{v}$ vs $\sigma$ curves shown in Fig. 6 , beyond which no pulsation occurred. The existence of upper limits to the $\sigma_{\mathrm{V}}$ vs $\sigma$ curves is probably attributable to the fact that at those upper limits cavities are so short and the influence of reentrant jets so great that practically no space is available for air to make the natural frequency of the cavity agree with that of the surface wave.

\section{B. Effect of Air Supply Rate}

When external air supply rate is kept constant the air inflow is balanced by the air outflow on the average, so that the amount of air stored in the cavity is kept nearly constant. This is one of the bases of the present quasi-steady, linear theory. That is, the theory assumes the air supply rate has no effect on the cavity pulsations as long as no stage-shift takes place.

Neglecting the part of the air carried out by turbulent diffusion across cavity walls, the only way the air can escapefrom the cavity is through the final wave length, indicated by dotted lines in the upper sketch of Fig. I(d), which breaks and separates from the main cavity. For the ideal case of zero air exchange as assumed in the theory, this final wave length which may be called the "residual cavity" must have zero volume. The residual cavity grows with the air supply rate. The maximum size of the residual cavity, however, cannotexceed the original wave size. Therefore, it can be concluded that each pulsating cavity must have its maximum air carrying capacity given by the following formula:

$$
\frac{W_{A}}{L}=g \rho_{a} f S_{0}^{\prime} / n
$$


where $\mathrm{W}_{\mathrm{A}}=$ weight rate of air supply,

$\mathrm{L}=\operatorname{span}$ length, and

$\rho_{a}=$ air density in cavity.

Using Eq. (10) and the fact that for long cavities [10]

$$
\begin{array}{ll}
S & \propto \sigma^{-3} \\
\ell & \propto \sigma^{-2}
\end{array}
$$

Equation (27) may be written in the following dimensionless forms:

$$
\sigma C_{W}=K^{\prime} \sqrt{I+\sigma}
$$

or for small $\sigma$

$$
\sigma c_{W} \approx K^{\prime}
$$

where $C_{W}$ is an air supply coefficient defined as

$$
C_{W}=\frac{W_{A}}{B L g \rho_{a} U}
$$

and $B$ is a characteristic dimension of the test body. Here the constant $K^{\prime}$ includes the various proportionality factors and the constant $K$ from Eq. (9a) which changes with reentrant jet and cavity size. It is therefore clear that $\mathrm{K}^{\prime}$ is not a universal constant, but rather a parameter varying with many factors. Since the interaction of the reentrant jet with the ventilating air is the main factor, $K$ is believed to be a function of both Reynolds number and Froude number as well as boundary conditions. In the freejet tunnel, however, the Froude number is unimportant so that for a given test body,

$$
\sigma \mathrm{C}_{W} \approx \mathrm{K}^{\prime} \text { (Re, boundary conditions) }
$$

It should be noted that $C_{W}$ is the air supply coefficient corresponding to maximum air supply ratefor each stage of pulsation of a given flow condition. To test the validity of Eq. (28b), data for a half span, 2-in. chord, flat plate hydrofoil testedin a 10-in. jet reported in [4] as well as datafor a 3-in. chord by 7-1/2-in. span flat plate hydrofoil testedin a towing tank by Wetzel and Schiebe [unpublished] are shown in Fig. 11. Since a 
half span 2-in. chord flat plate in the free jet tunnel is equivalent to a 2-in. chord by 5-in. span flat plate in a towing tank, the two test bodies have equal aspect ratio of 2.5. Solid lines shown in Fig. 11 are for Eq. (28b) with $K^{\prime}$ equal to 0.014 and 0.010 respectively. The present theory and the experimental data are not sufficient to determine the variable constant $K^{\prime}$ completely for all flow conditions.

Figure 7 demonstrates the fact that the air supply rate has little effect on the amplitude of pulsation. Frequency data of Fig. 5 cover a wide range of air supply rates, varying from 1 to 9 times critical air supply rates, and yet the scatter is considered to be small. In fact the maximum frequency change due to air supply change was observed to be of the order of 10 per cent.

\section{Other Effects}

\section{Boundary Conditions}

It cannot be denied that the mathematical model of the present theory is very simple compared to the actual flow conditions which it trys to represent. For cavities in a free-jet tunnel where two free surfaces exist, the approximation should not be as serious as for the cavities in a towing tank where only one free surface exists. In view of the rather good agreement between data and the theoretical results, the error due to the oversimplification of the boundary condition in the former case is believed to be small. The answer to the question as to how well the present theory approximates the latter case must await more experimental data or the development of a more refined theory. However, it is clear that the existence of a free surface is a necessary condition for this kind of pulsation to occur. It may also safely be said that pulsation is more likely to occur when a free surface is close to a cavity than when it is remote. This means that, in an open sea, submergence is an important criteria determining pulsation.

One other factor which may affect the accuracy of the theory is the size of the air space surrounding the jet in the free-jet tunnel. Due to the physical limitation of the tunnel, this bounding air space is finite whereas the theorytreated the case when the bounding space is infinite. Finite bounding space leads to a variable bounding pressure and, therefore, leads to a different solution. A problem of this kind should not be difficult to solve. In fact, the only modification required is to have an additional term in Eq. 
(3) representing the P. E. of the air bounding the jet. However, the detailed calculation will not be included in this paper.

Finally, an interesting topic is the significance of the reentrant jet on the pulsating cavities. (The reentrant jet is also the main feature determining the air entrainment capacities of steady cavities. Detailed discussion of this will not be included here.) As was mentioned earlier, the reentrant jet regulates the amount of space available for air in the cavity so that the natural frequency of the air-water system can be made compatible with Eq. (Ib). Suppose, for some reason or other, that the strength of the reentrant jet is restricted. Then the regulatory power of the reentrant jet is reduced and the cavity will not pulsate so easily. To test out this idea, a wedge was made so that a long thin plate could be attached to the rear end of the wedge dividing the cavity into two parts. This plate served not only as a partition wall, but also served to reduce the strength of the reentrant jet by friction. Remarkably enough, this partition wall eliminated the pulsation almost completely. This finding may have an important application to practical problems of artificial cavities. However, the detailed discussion of this problem is considered as outside of the scope of this paper and will be discussed in later reports.

\section{Cavity Shape}

The greatest source of error should be expected from the assumption that the cavity is a circular cylinder. The vibratory flow of the liquid bounding the cavity will not be radial if the cavity cross section is not a circle. The error increases as the cavity becomes more slender. Moreover, for unsymmetrical bodies like hydrofoils, the resulting cavity shape is not symmetrical, and thus it deviates even more from a circle. To completely eliminate errors of this type, the actual flow conditions should be considered; that is, the steady flow part and the vibratory flow part cannot be separated as was done in this theory. A general theory of unsteady cavities in a finite fluid with free surface is required.

\section{Compressibility and Viscosity of Water}

If one examines Eqs. (5) and (23) it is apparent that both the kinetic energy and the pressure are logarithmically singular if the liquid extends to infinity. Moreover, when $R_{0}$ is large, there is a large volume of water surrounding the cavity, and small local compressions may sum up to a 
significant value. These facts point out that the compressibility of water may become important when jet width or submergence is large.

The greater the viscosity the greater the viscous loss. ConsequentIy, the greater the viscosity the weaker the reentrant jet. For the reason stated in paragraph I, above, therefore, the cavity should be more difficult to pulsate for a highly viscous liquid than for a low viscosity liquid.

4. Gravitation

As was statedin the introduction, a phenomenon pertinent to gravitational effect is the appearance of vortex tubes. When both gravitational force and a free surface exist, as in the case of towing tank experiments, the relative importance of the two factors must depend upon the relative thickness of the cavity and the relative depth of submergence. For large relative thickness and relative submergenceit is likely that vortex tubes will occur, and conversely, for small relative thickness and relative submergence, a pulsating cavity is likely. Whether the two phenomena can occur simultaneously or not is a question that cannot yet be answered.

\section{Non-linearity}

The present theory is based upon an assumption that the amplitude of pulsation is small so that the second or higher order terms may be neglected. It is therefore expected that the theory will apply better to weaker pulsations than to stronger pulsations. By Eq. (18), pulsations are weaker for higher-stage cavities than for lower-stage cavities. This leads to the expectation that the theory should be better applicable to high-stage cavities than to low-stage cavities. This is probably why Eq. (16) fits the data from fourth- and higher-stage cavities better than the data from lower stages as shown in Fig. 7 .

A non-linear differential equation corresponding to Eq. (8) has been derived, but it appears that the solution can be obtained only by a numerical integration method. No attempt has been made to solve the equation.

\section{CONCLUSIONS}

The result of the analysis and the experimental data have proved the validity of the assumption that pulsation of ventilated cavities is a peculiar phenomenon of mechanical resonance of the air-water system which occurs when 
one or more free surfaces exist. It is the motion of surface waves on the cavity walls which causes the cavity to changeits volume periodically. This periodical volume change is accompanied by a vibratory motion of the surrounding water and a pressure pulsation in the cavity. The pulsation is possible only when the natural frequency of the air-water system agrees with the frequency of the surface waves.

There may be any integral number of surface waves appearing on a cavity wall, from one to infinity. Hence, pulsating cavities may be classified according to the number of waves and called first-stage, second-stage, etc. To each stage there corresponds a definite amplitude of pulsation and air carrying capacity. It is also noteworthy that both frequency and amplitude of pulsations are very insensitive to air supply rate change. The formula relating $\sigma_{\mathrm{v}}$ and $\sigma$ [Eq. (16)] permits prediction of the beginning of pulsation for a given natural cavity.

The results presented in this paper should be applicable to all shapes of test bodies as long as they are two-dimensional or nearly two-dimensional, since the shape does not appear explicitly in the analysis. It is also an important conclusion thatin an open sea only when the submergence is relatively small may pulsation become a matter of concern.

As was observed in Section V, there are many sources of inaccuracies, and therefore care must be taken when the present theory is to be applied to different flow conditions. It is believed that the present theory is only a first step toward the complete understanding of the complicated problem of pulsating cavities in particular, and ventilated cavities in general. 


$$
\underline{L} \underline{I} \underline{S} \underline{T} \quad \underline{O} \underline{F} \quad \underline{R} \underline{E} \underline{F} \underline{E} \underline{R} \underline{E} \underline{N} \underline{C} \underline{E} \underline{S}
$$

[1] Cox, R. N. and Clayden, W. A。 "Air Entrainment at the Rear of a Steady Cavity," Proceedings of the N. P. L. Symposium on Cavitation in Hydrodynamics, Paper No. 12, London. 1955. 19 pages.

[2] Campbell, I. J. and Hilborne, D. V. "Air Entrainment Behind Artificially Inflated Cavities," Second Symposium on Naval Hydrodynamics, Washington D. C。 August 1958 .

[3] Lang, Thomas G. and Daybell, Dorothy A. Water-Tunnel Tests of a BaseVented Hydrofoil Having a Cambered Parabolic Cross Section. NAVORD Report No. 7-584, China Lake, Califormia. October 10, 1960.

[4] Silberman, E. and Song, C. S。 Instability of Ventilated Cavities. University of Minnesota, St. Anthony Falls Hydraulic Laboratory Technical Paper No. 29-B, Minneapolis, Minnesota. November 1959.

[5] Wetzel, J. Mo and Schiebe, F。 R. Experimental Studies of Artificial Cavities on Submerged Hydrofoils of Finite Span. University of Mininesota, St. Anthony Falls Hydraulic Laboratory Memorandum No. M-89, Minneapolis, Minnesota. November 1960.

[6] Cuthbert, Jerry W. An Analysis of Air Entrainment in Cavity Flows. Hydronautics, Inc. Technical Report 003-1, Rockville, Maryland. October 10, 1960.

[7] Devin, Charles Jr. Survey of Thermal Radiation and Viscous Damping of Pulsating Air Bubbles in Water. David Taylor Model Basin Report No. 1329. August 1959.

[8] Strasberg, N. "The Pulsation Frequency of Nonspherical Gas Bubbles in Liquids," Journal of the Acoustical Society of America, Vol. 25, p. 536. 1953。

[9] Milne-Thomson, L. M。 Theoretical Hydrodynamics, 3rd Edition. New York: Macmillan Company, p. 509. 1955.

[10] Wu, T. Yao-Tsu. A Simple Method for Calculating the Drag in the Linear Theory of Cavity Flows. California Institute of Technology, Engineering Division Report No. 85-5. August 1957. 
$\underline{F} \underline{I} \underline{G} \underline{\mathrm{R}} \underline{\mathrm{E}} \underline{\mathrm{S}}$

(I through 1I) 


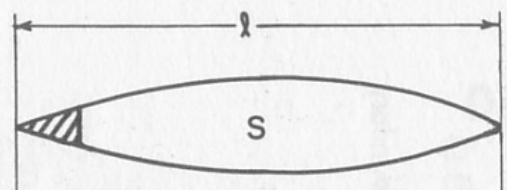

(a) Steady cavity profile just before pulsation

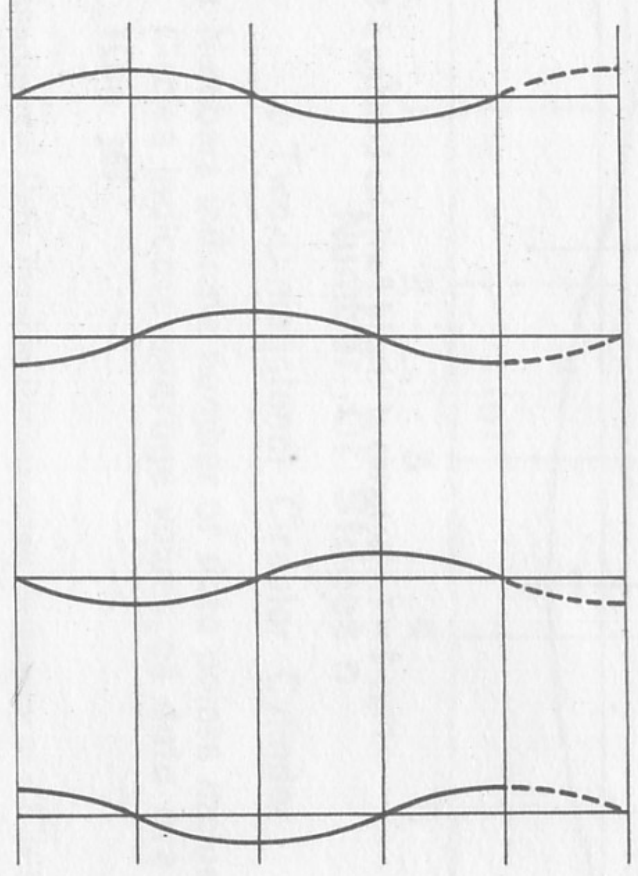

(b) Uniform traveling wave

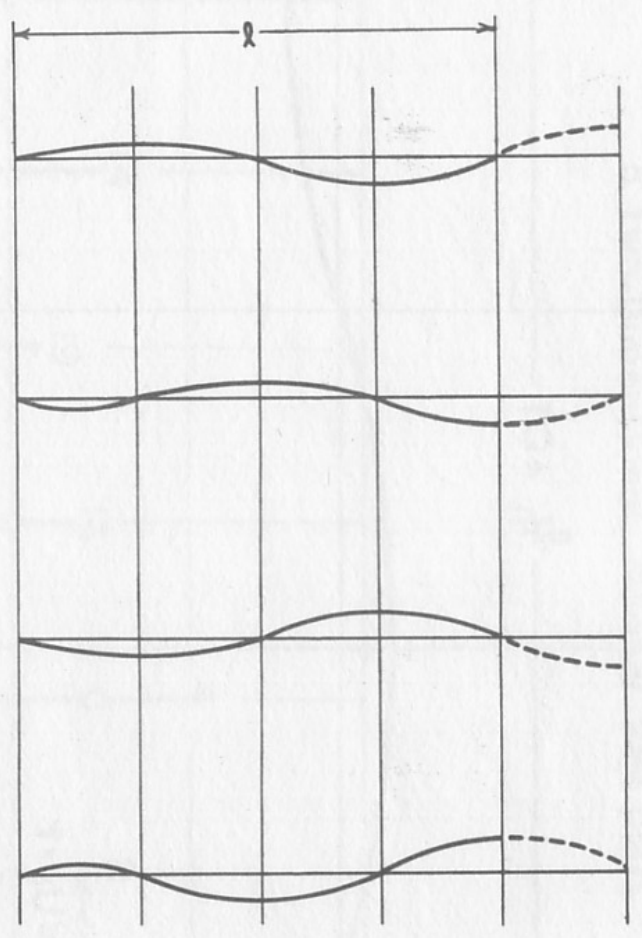

(c) Actual non-uniform traveling wave

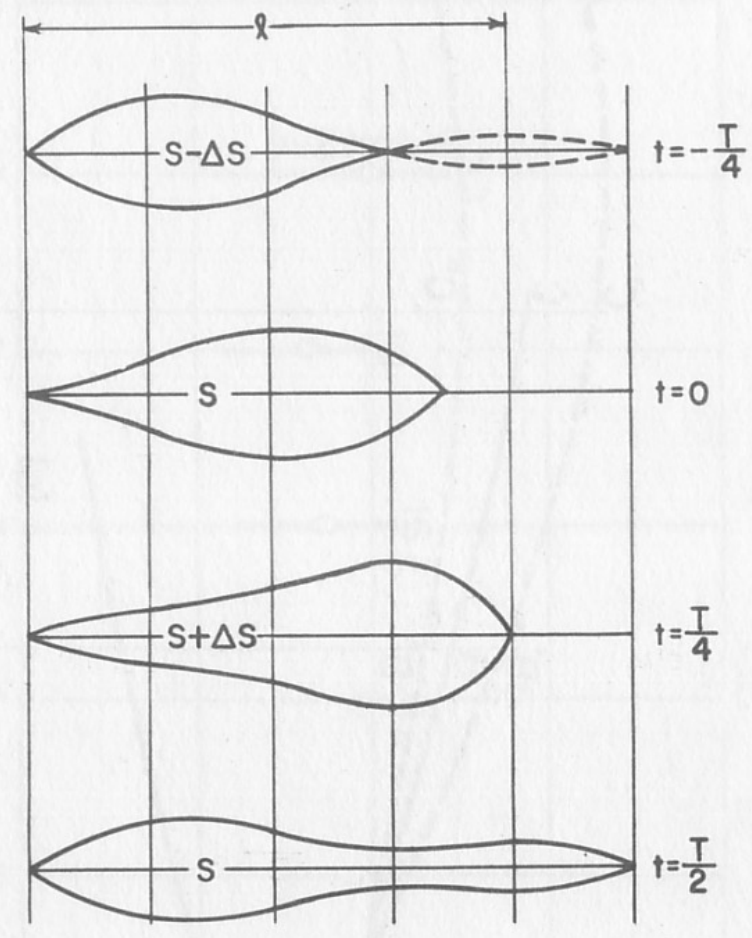

(d) Pulsating cavity profile

Fig. 1 - Kinematics of First-Stage Pulsating Cavity 


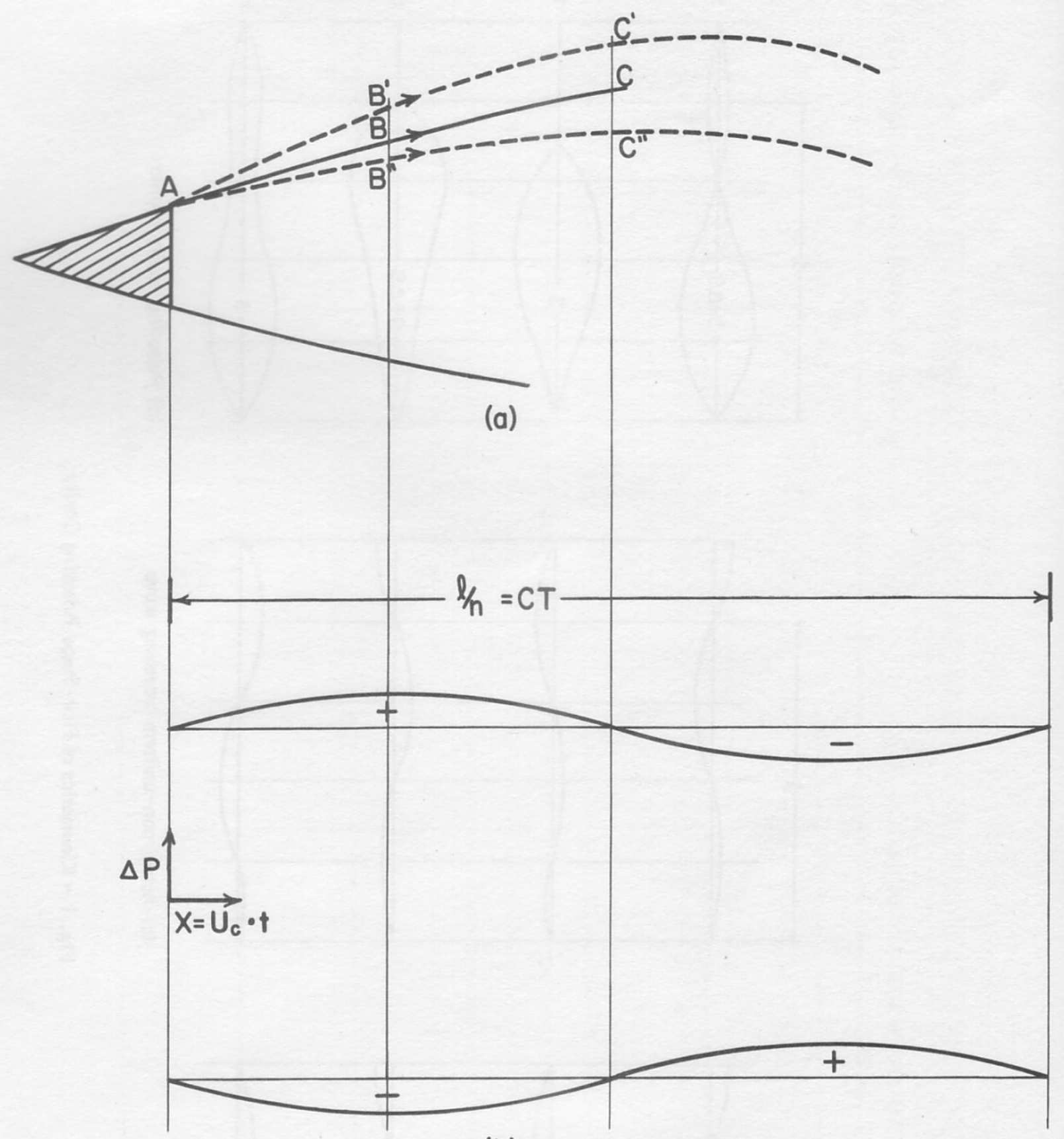

(b)

Fig. 2 - Trajectories of Liquid Particles Leaving a Solid Boundary 

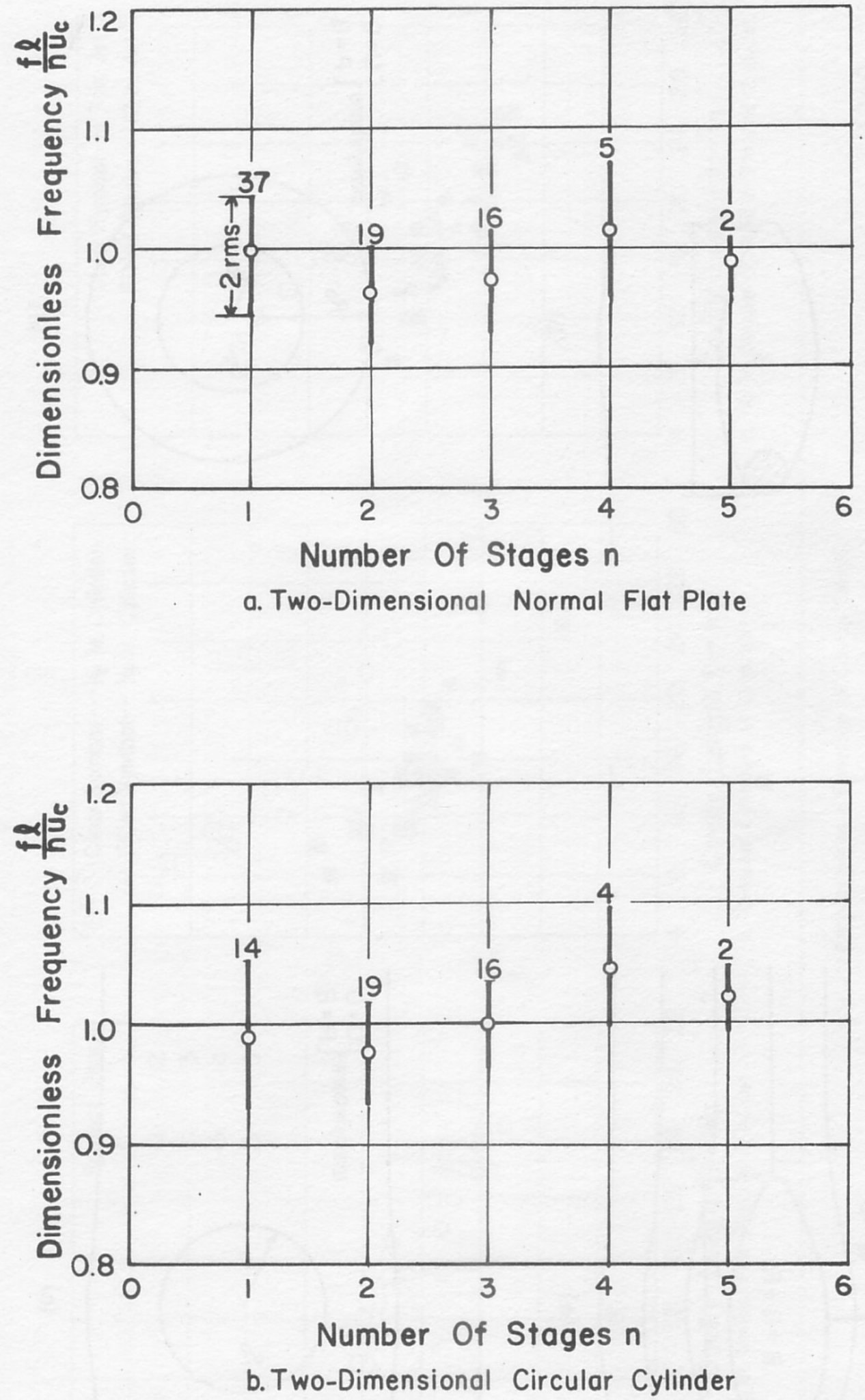

Note: Numbers indicate number of dato points included, Circles indicate average values, all data are for IOin. jet

Fig. 3 - Experimental Data Showing Dimensionless Frequency as a Function of 
$P_{\infty}$

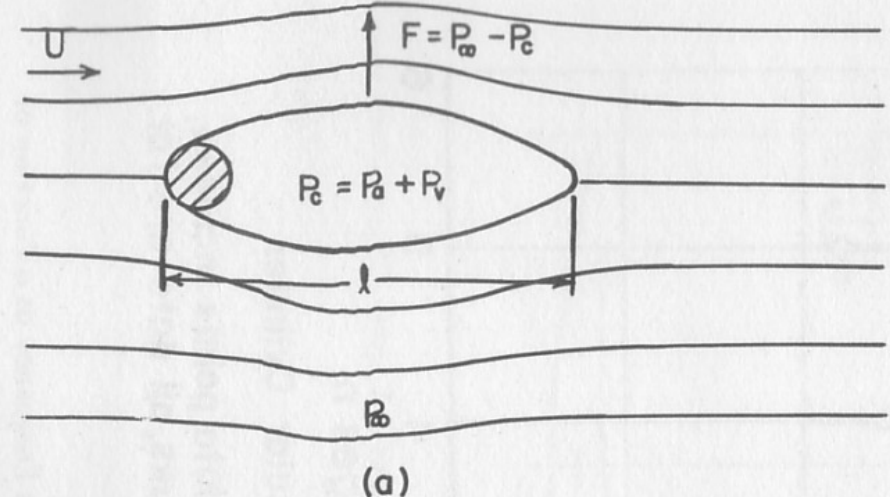

(a)

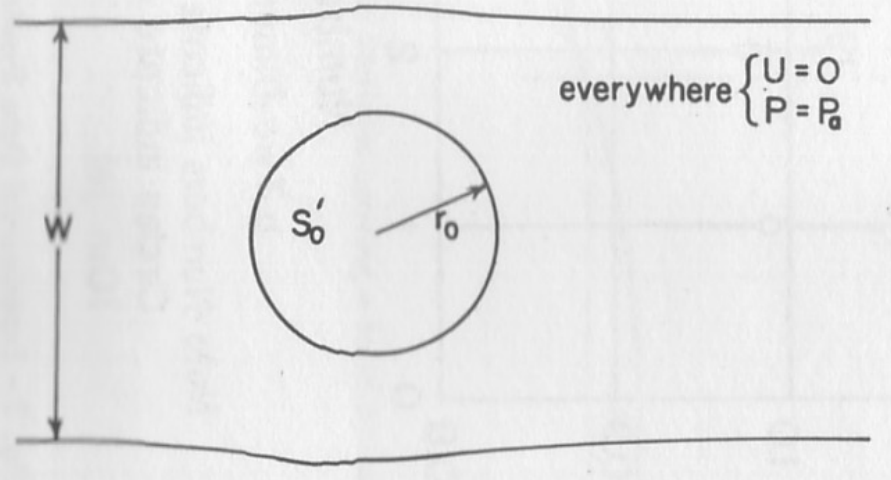

(c)

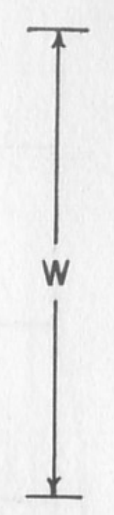

(b)

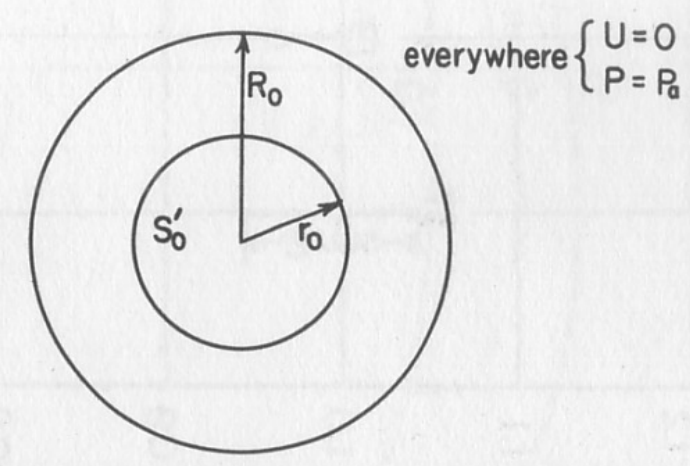

(d)

Fig. 4 - Pulsating Cavity Model 


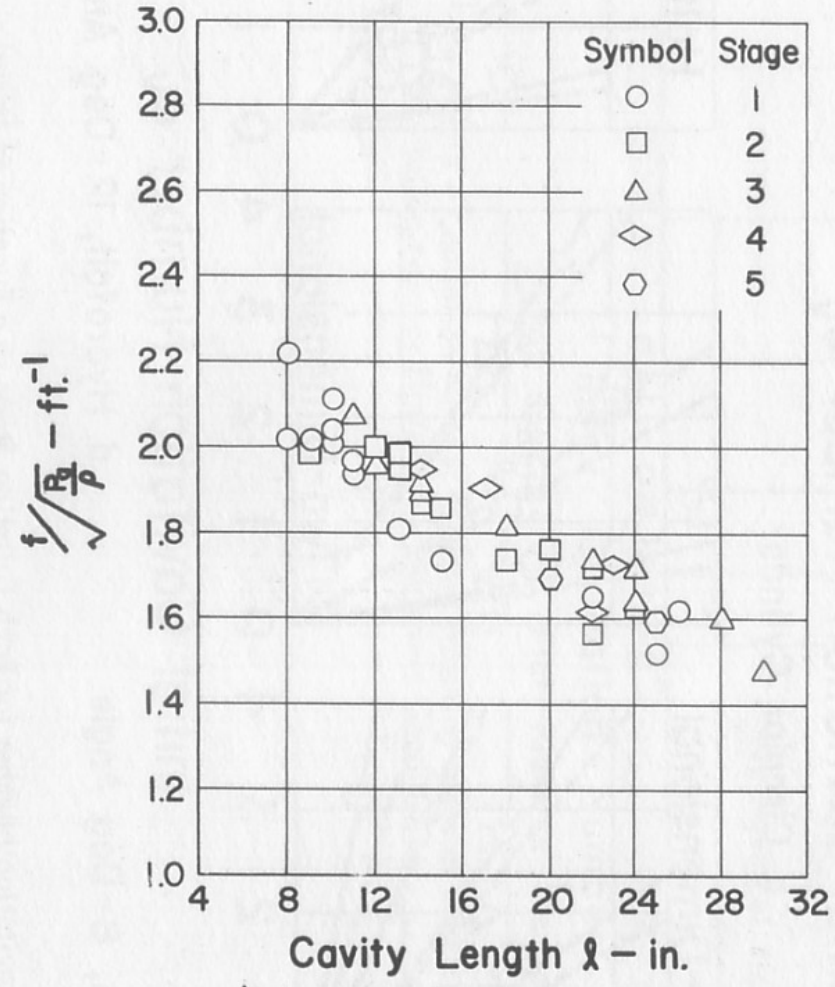

a. $1 / 8$ in. Normal Flat Plate in 10 in. Jet

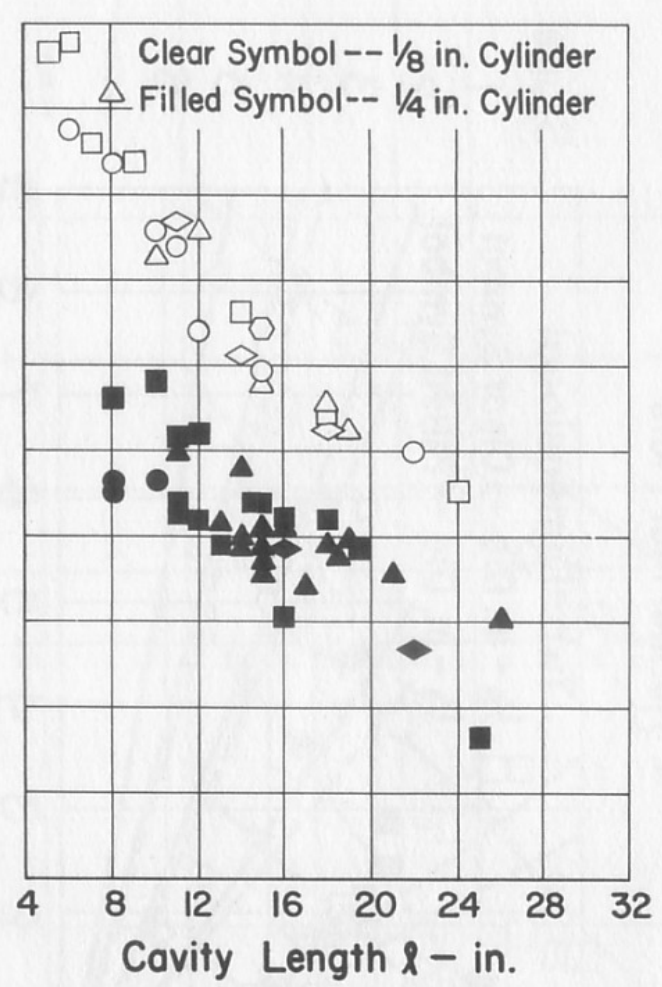

b. Circular Cylinders in 10 in. Jet

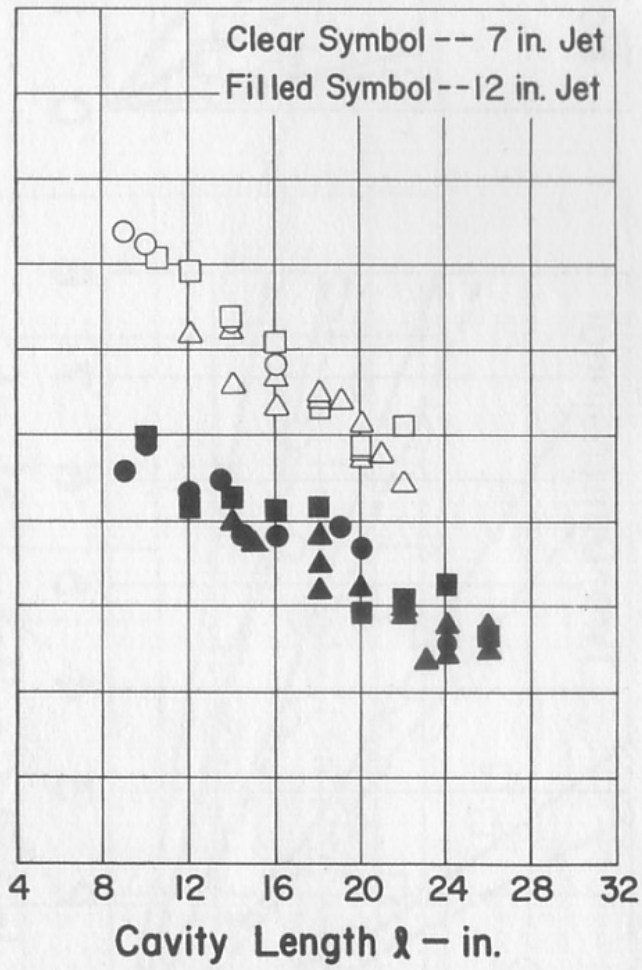

c. $1 / 4$ in. Circular Cylinder in 7 in. and 12 in. Jet

Fig. 5 - Frequency as a Function of Cavity Length 

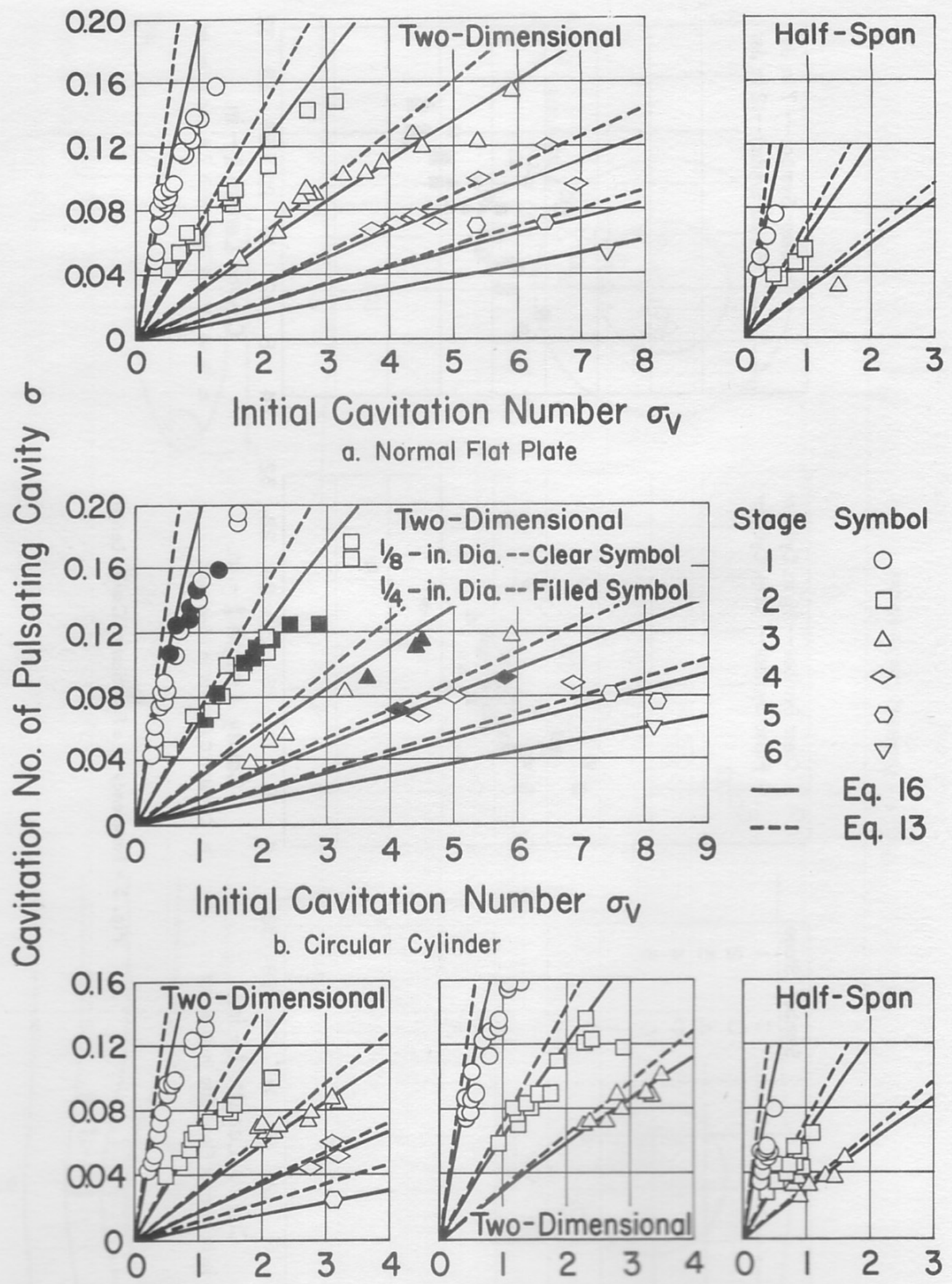

Initial Cavitation Number $\sigma_{\mathrm{V}}$
c. Hydrofoil A, 8-Deg. Angle
d. Hydrofoil, 12 - Deg. Angle

Fig. 6 - Cavitation Number for Each Pulsating Stage as a Function of Initial 


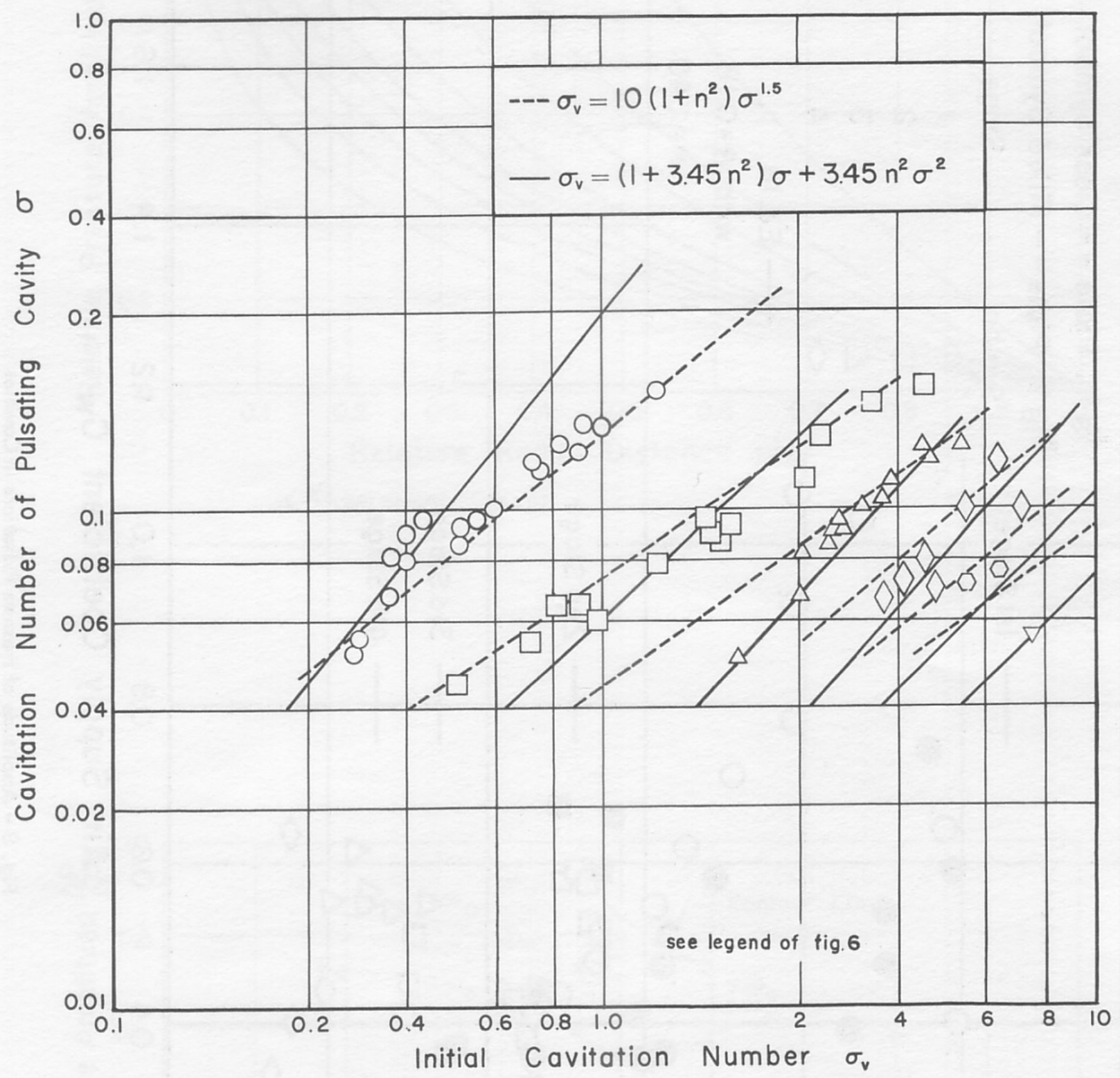

Full Span, Normal Flat Plate In IO in. Jet

Fig. 7 - Cavitation Number for Each Pulsating Stage as a Function of Initial Cavitation Number Plotted on Logarithmic Coordinates 


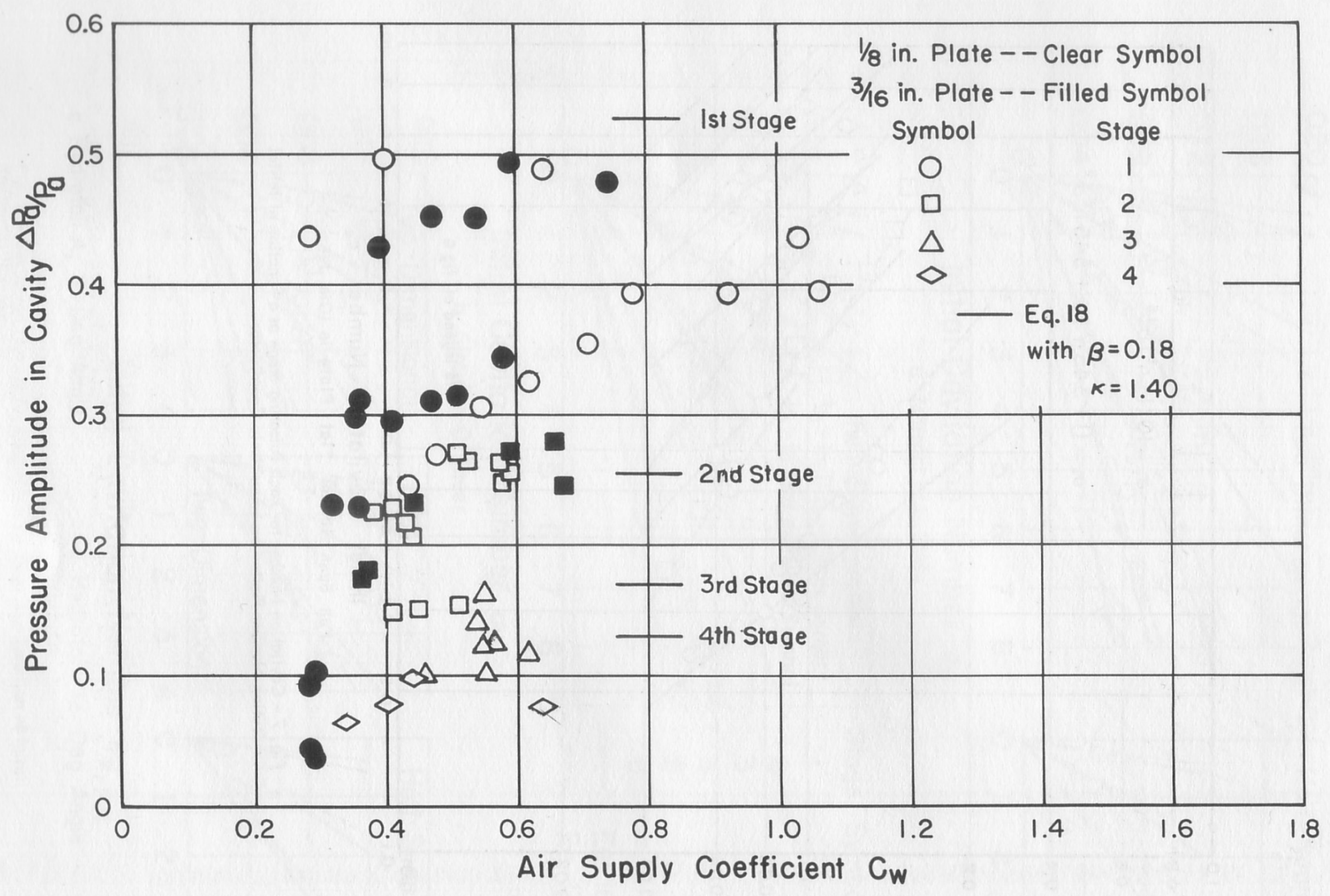

Fig. 8 - Amplitude of Pressure Pulsations in Cavities 


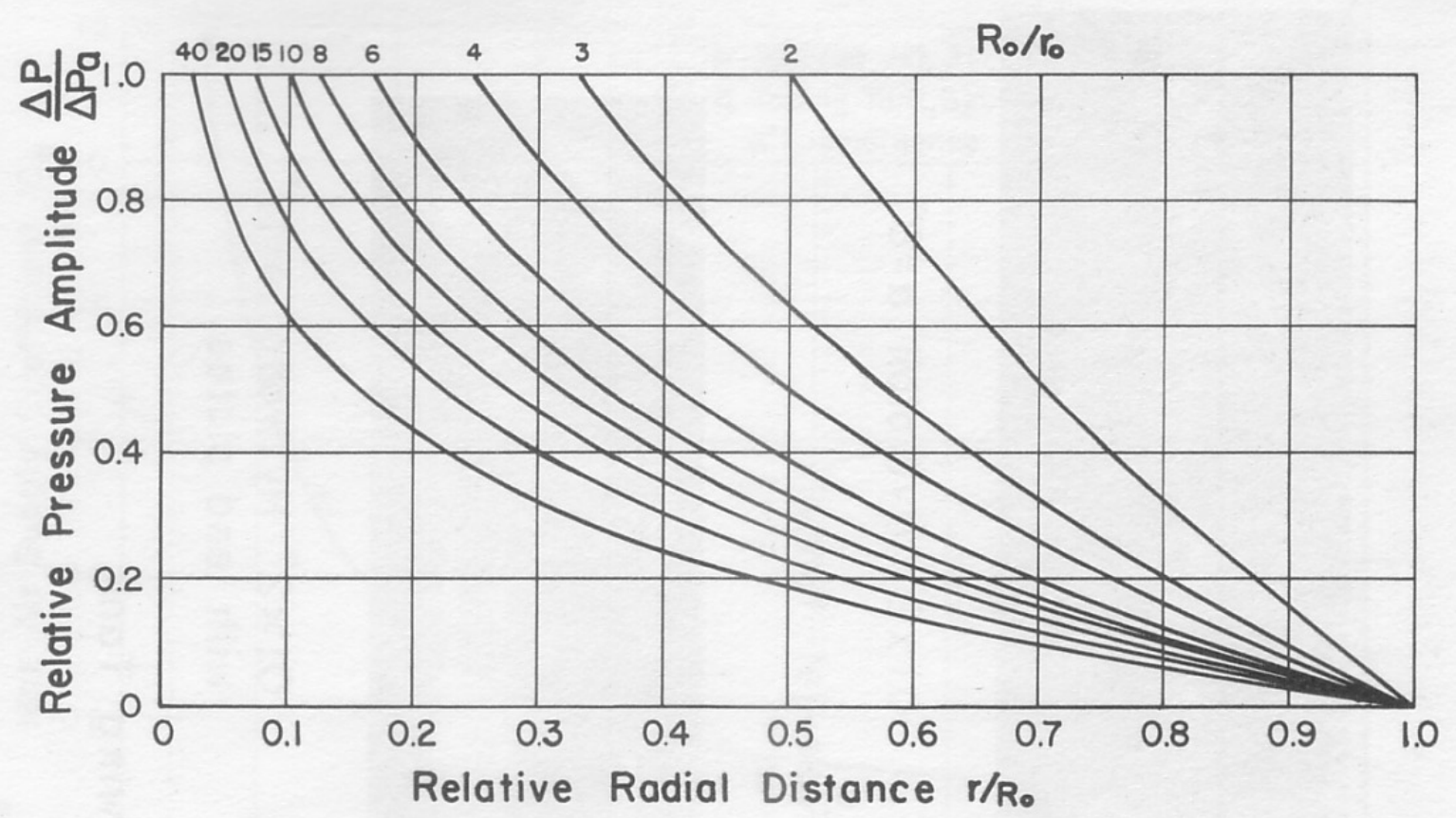

a. Theoretical Curves

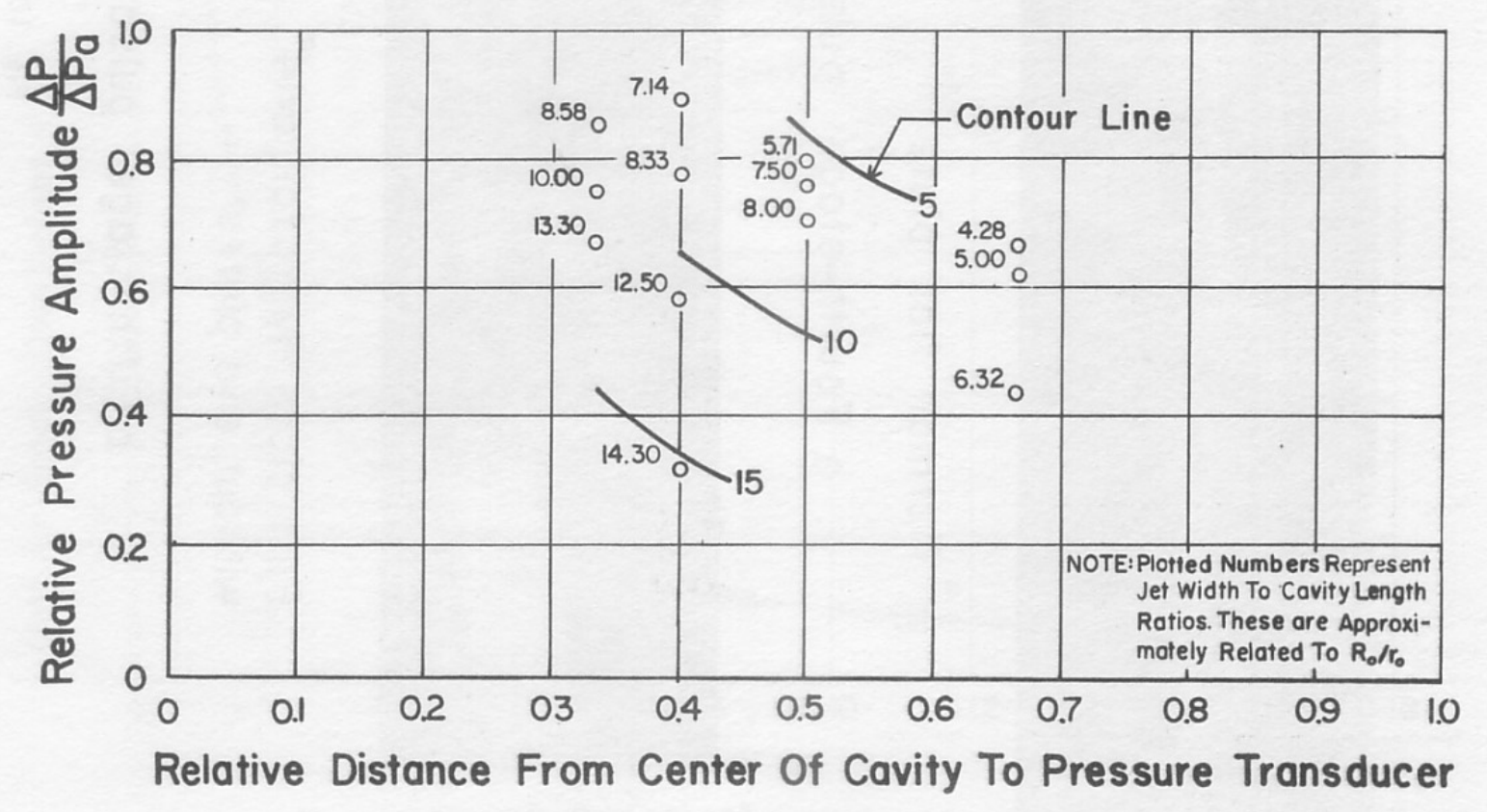

b. Experimental Data

Fig. 9 - Relative Amplitude of Pressure Pulsations in Water Outside Cavity 


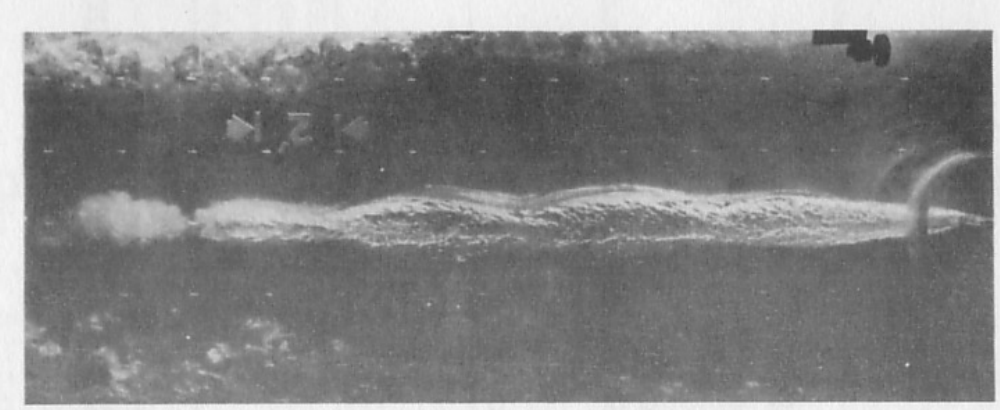

$\frac{1}{8} "$ Normal flat plate

a. Fourth-stage pulsating

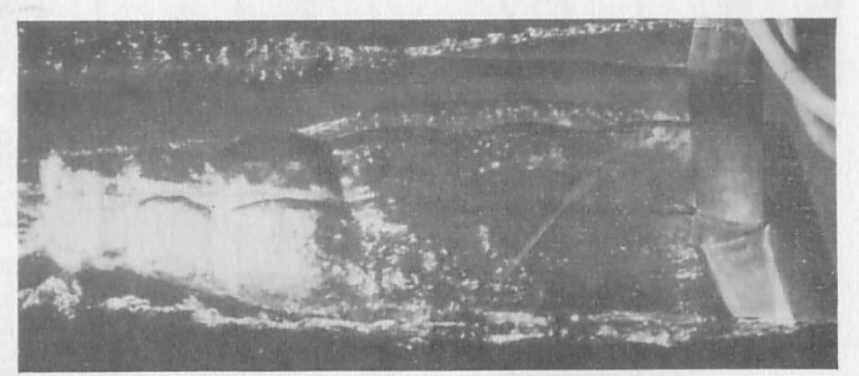

Flat plate Hydrofoil, $\alpha=14^{\circ}$ without end plates

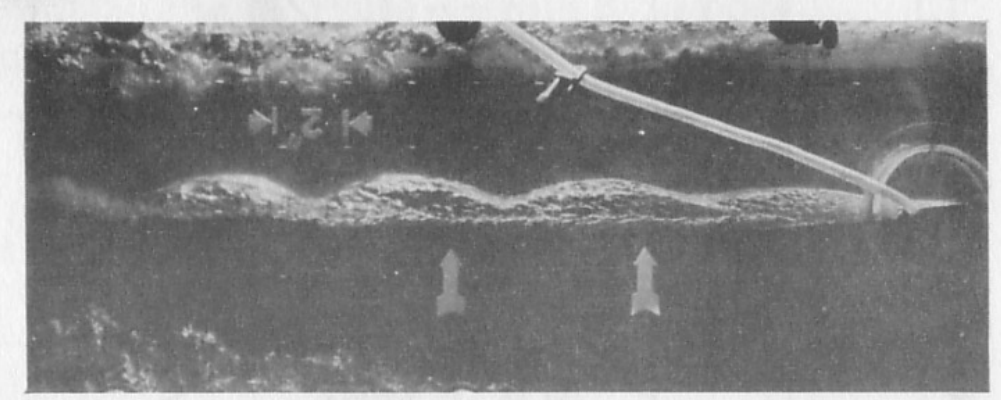

$0.1 \times 2^{\circ}$ Hydrofoil, $\alpha=8^{\circ}$

cavities in Free-jet tunnel

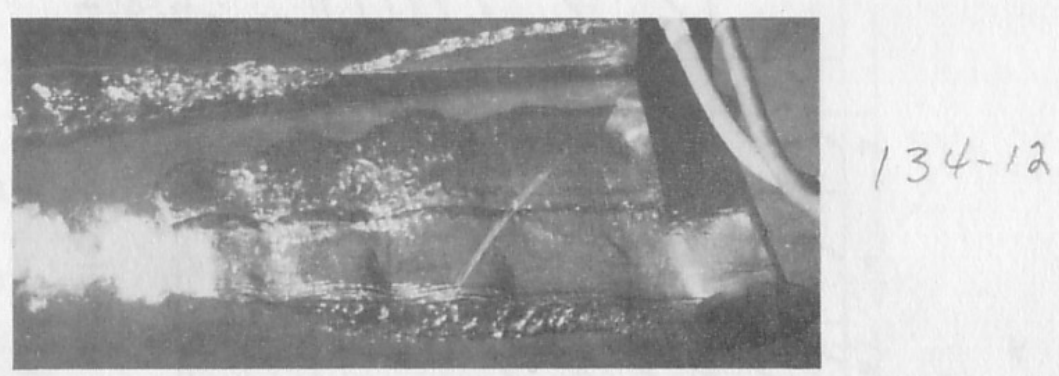

O.I $\times 2^{\circ}$ Hydrofoil, $a=17^{\circ}$ with end plates

b. Fifth-stage pulsating cavities in Towing Tank

Fig. 10 - Photographs of Pulsating Cavities 


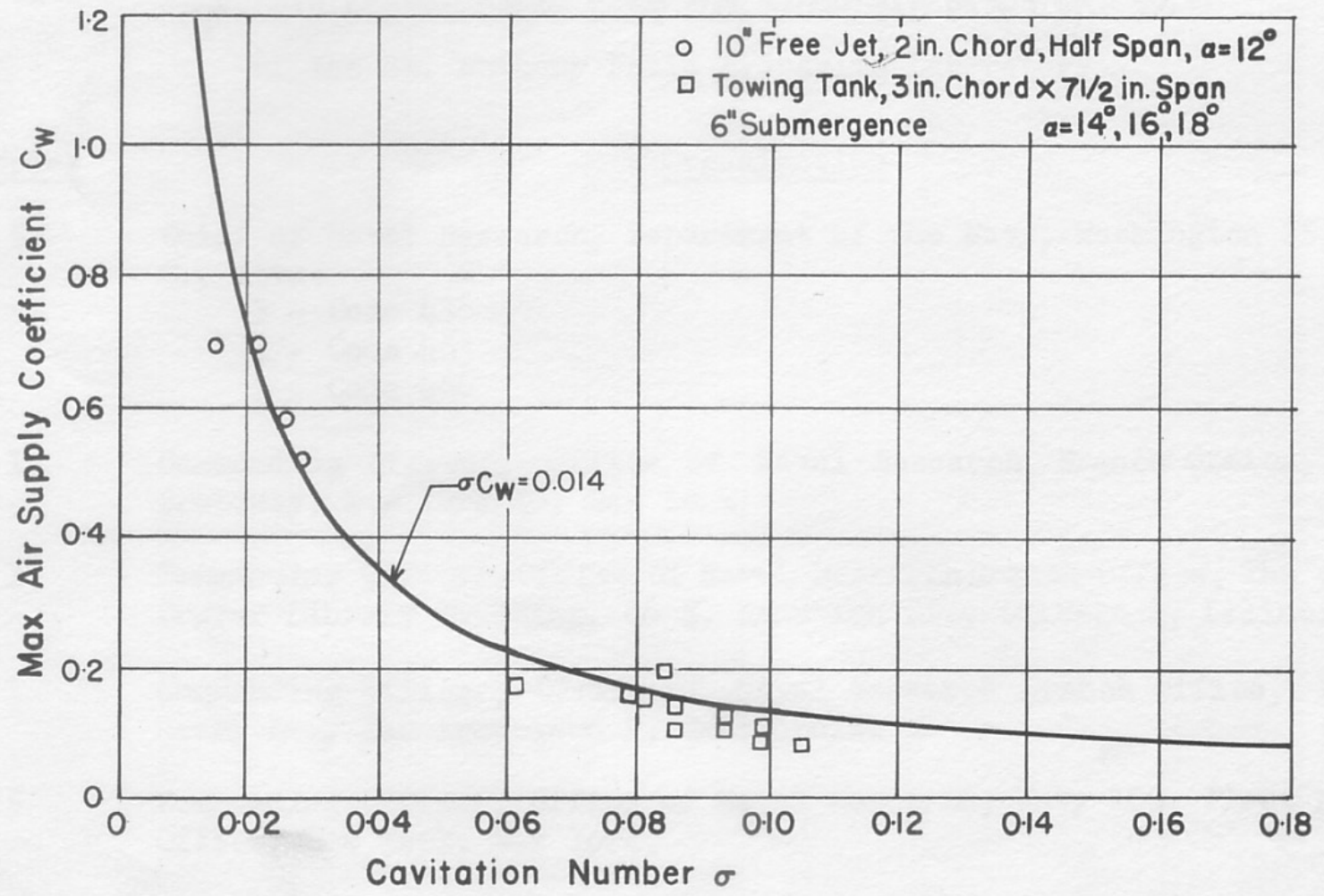

a. For $1.6 \times 10^{5}<\operatorname{Re}<2.5 \times 10^{5}$

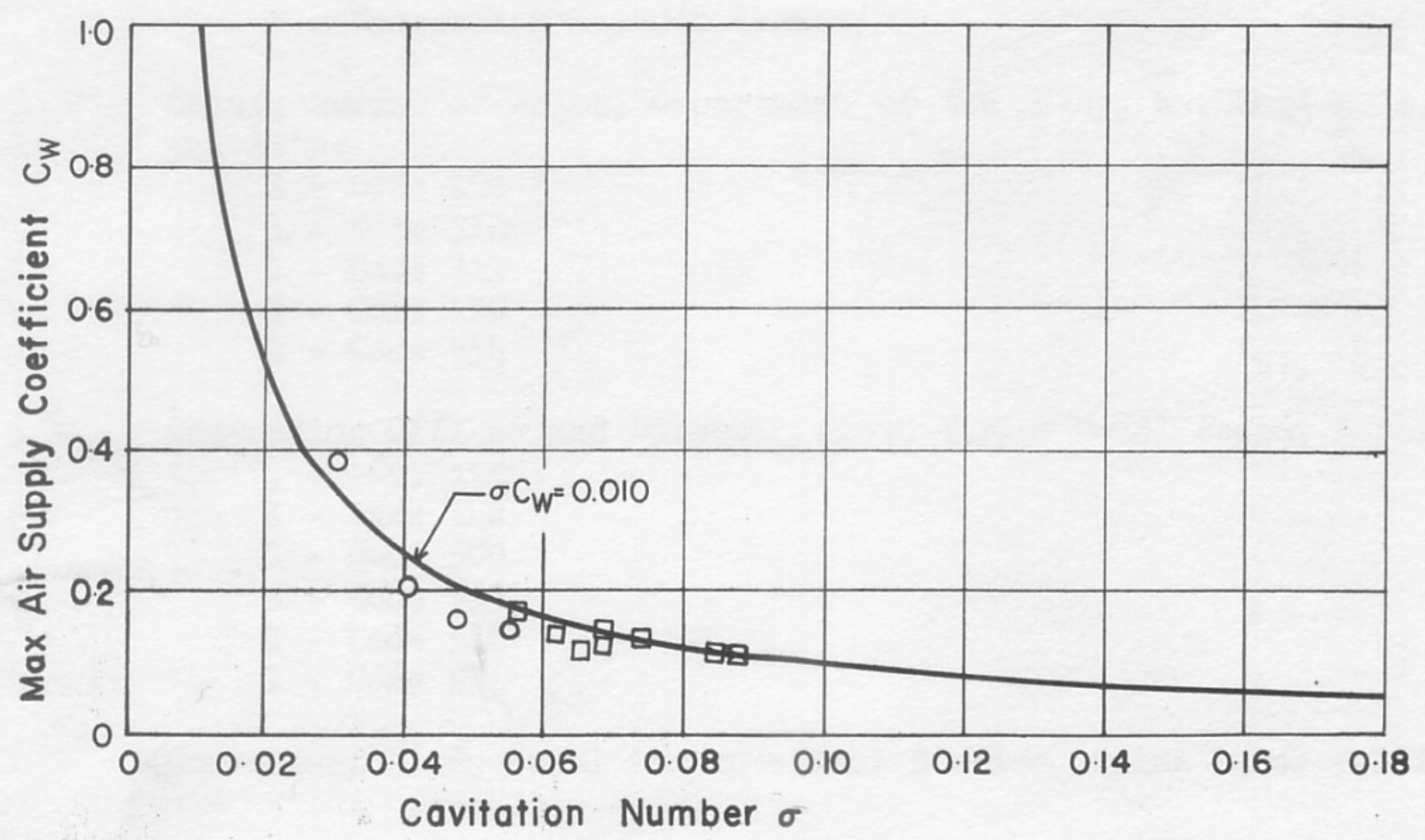

b. For $3.0 \times 10^{5}<\operatorname{Re}<3.5 \times 10^{5}$

Fig. 11 - Air Supply Rate for Pulsating Cavities 
SPONSOR'S DISTRIBUTION LIST FOR TECHIICAL PAPER NO. 32-B

of the St. Anthony Falls Hydraulic Laboratory

Copies

Organization

5

Chief of Naval Research, Department of the Navy, Washington 25, D. C., Attn:

$$
\begin{aligned}
& 3 \text { - Code } 438 \\
& 1 \text { - Code } 463 \\
& 1 \text { - Code } 466
\end{aligned}
$$

1 Commanding Officer, Office of Naval Research Branch Office, 346 Broadway, New York 13, New York.

1 Commanding Officer, Office of Naval ResearchBranch Office, The John Crerar Library Building, 86 E. Randolph St., Chicago I, Illinois.

1 Commanding Officer, Office of Naval Research Branch Office, 1000 Geary St., San Francisco 9, California.

25 Commanding Officer, Office of Naval Research, Navy 100, Fleet Post Office, New York, New York.

6 Director, Naval Research Laboratory, Washington 25, D. C., Attn: Code 2000.

4 Chief, Bureau of Naval Weapons, Department of the Navy, Washington 25, D. C., Attn:

1 - Aero and Hydro Branch

1 - Research Division

2 - Underwater Missile Branch

5 Chief, Bureau of Ships, Department of the Navy, Washington 25, D. C., Attn:
1 - Code 106
1 - Code 310
1 - Code 312
1 - Code 420
1 - Code 554

5 Commanding Officer and Director, David Taylor Model Basin, Washington 7, D. C., Attn:

1 - Code 142

1 - Code 500

1 - Code 513

1 - Code 526

1 - Code 591

1 Commander, U. S. Naval Ordnance Test Station, China Lake, California, Attn: Code 753.

1 Officer-in-Charge, Pasadena Annex, U. S. Naval Ordnance Test Station, 3202 E. Foothill Boulevard, Pasadena, California, Attn: Code P890962. 
Commanding Officer and Director, U. S. Naval Engineering Experiment Station, Annapolis, Maryland.

1 Commander, Naval Proving Ground, Dahlgren, Virginia, Attn: Technical Library Division (AAL).

1 Commanding Officer, U. S. Naval Underwater Ordnance Station, NewPort, Rhode Island, Attn: Research Division.

1 Commander, U. S. Naval Ordnance Laboratory, White Oak, Maryland, Attn: Library Division (Desk HL).

$1 \quad$ Mr.Wo I. Niedermair, Coordinator of Research, Maritime Administration, 441 G Street, N. W., Washington 25, D. C.

3 National Bureau of Standards, Washington 25, D. C., Attn:

I - Fluid Mechanics Section

I - Dr。G. B. Schubauer

I - Dr. G. H. Keulegan

1 National Academy of Sciences, National Research Council, 2101 Constitution Avenue, N. Wo, Washington, D. C.

1 Superintendent, U. S. Naval Academy, Annapolis, Maryland, Attn: Librarian.

1 Superintendent, U. S. Naval Postgraduate School, Monterey, California, Attn: Librarian.

I Superintendent, U. S. Merchant Marine Academy, Kings Point, Long Island, New York, Attn: Captain I. S。 McCready, Head, Department of Engineering.

1 Air Force Office of Scientific Research, Mechanics Division, Washington $25, \mathrm{D}, \mathrm{C}$ 。

1 Commanding Officer, Office of Ordnance, Box CM, Duke Station, Durham, North Carolina.

5 Director of Research, National Aeronautics and Space Agency, 1512 H Street, No Wo, Washington 25, D。C.

2 Mr.J. B. Parkinson, Langley Aeronautical Laboratory, National Aeronautics and Space Administration, Langley Field, Virginia.

1 Director, Engineering Sciences Division, National Science Foundation, $1520 \mathrm{H}$ Street, N. W., Washington, D. C.

10 Document Service Center, Armed Services Technical Information Agency, Arlington Hall Station, Arlington 12, Virginia.

Office of Technical Services, Department of Commerce, Washington 25, D. C. 
California Institute of Technology, Pasadena 4, California, Attn:

1 - Professor Mi: S. Plesset

1 - Professor T. Y. Wu

1 - Professor A. Acosta

1 - Hydro Lab

University of California, Berkeley 4, California, Attn:

1 - Department of Engineering

I - Professor H. A. Schade

1 - Professor J. V. Wehausen

1 Director, Scripps Institution of Oceanography, University of California, La Jolla, California.

1 Professor M. Albertson, Department of Civil Engineering, Colorado State University, Fort Collins, Colorado.

IowaInstitute of Hydraulic Research, State University of Iowa, Iowa City, Iowa, Attn:

1 - Professor H. Rouse, Director

I - Professor L。 Landweber

2 Harvard University, Cambridge 38, Massachusetts, Attn:

1 - Professor G. Birkhoff, Department of Mathematics

1 - Professor G. F. Carrier, Division of Engineering and Applied Physics

3 Massachusetts Institute of Technology, Cambridge 39, Massachusetts, Attn:

1 - Department of $N_{0} A_{\text {, and }} \mathrm{M}_{\mathrm{B}} \mathrm{E}$.

I - Professor A. T. Ippen, Hydro Laboratory

1 - Library

4 University of Michigan, Ann Arbor, Michigan, Attn:

I - Professor R. B. Couch, Department of N. A, and M. E.

1 - Professor C. S. Yih, Department of Engineering Mechanics

I - Professor V. Streeter, Department of Civil Engineering

1 - Library

1 Director, St. Anthony Falls Hydraulic Laboratory, University of Minnesota, Minneapolis 14, Minnesota.

1 Director, Alden Hydraulic Laboratory, Worcester Polytechnic Institute, Worcester, Massachusetts.

1 Director, Ordnance Research Laboratory, Pennsylvania State University, University Park, Pennsylvania.

1 Director, Institute of Mathematical Sciences, New York University, 25 Waverly Place, New York 3, New York.

Professor J. J. Foody, Engineering Department, New York State University, Maritime College, Fort Schulyer, New York. 
Technical Library, Webb Institute of Naval Architecture, Crescent Beach Road, Glen Cove, Long Island, New York.

1 Professor S. Corrsin, Chairman, Mechanical Engineering Department, The Johns Hopkins University, Baltimore, Maryland.

1 Commanding Officer, Office of Naval Research Branch Office, 1030 East Green Street, Pasadena 1, California.

1 Director, Woods Hole Oceanographic Institute, Woods Hole, Massachusetts.

1 Society of Naval Architects and Marine Engineers, 74 Trinity Place, New York 6, New York.

1 Engineering Societies Library, 29 W. 39th Street, New York 18, New York.

Stevens Institute of Technology, Davidson Laboratories, 711 Hudson Street, Hoboken, New Jersey, Attn:

$$
\begin{aligned}
& 1 \text { - Dr. J. Breslin } \\
& 1 \text { - Mr. D. Savitsky } \\
& 1 \text { - Library }
\end{aligned}
$$

1 Director, Institute for Fluid Mechanics and Applied Mathematics, University of Maryland, College Park, Maryland.

1 Division of Applied Mathematics, Brown University, Providence 12, Rhode Island.

I Hydrodynamics Laboratory, National Research Council, Ottawa, Canada.

1 Professor L. M. Milne-Thomson, Mathematical Research Center, 1118 W. Johnson Center, Madison 6, Wisconsin.

1 Dr. J. M. Robertson, Department of Theoretical and Applied Mechanics, College of Engineering, University of Illinois, Urbana, Illinois.

2 Stanford University, Stanford, California, Attn:

1 - Professor J. K. Venard, Civil Engineering Department

1 - Applied Mathematics and Statistics Laboratory

1 Professor J. B. Herbich, Civil Engineering Department, Leheigh University, Bethlehem, Pennsylvania.

1 Dean J. S. McNown, Department of Engineering Mechanics, University of Kansas, Lawrence, Kansas.

1 Professor A. G. Strandhagen, Department of Engineering Mechanics, University of Notre Dame, Notre Dame, Indiana. 
Polytechnic Institute of Brooklyn, Department of Aeronautical Engineering and Applied Mechanics, 333 Jay Street, Brooklyn 1, New York, Attn:

1 - Professor A. Ferri

1 - Professor H. Reissner

Professor H. Cohen, IBM Research Center, P. O. Box 218, Yorktown Heights, New York.

1 Professor D. Gilbarg, Applied Mathematics and Statistics Laboratory, Stanford University, Stanford, California.

$1 \quad$ Mr. Leo Geyer, Chief of Preliminary Design, Grumman Aircraft Engineering Corporation, Bethpage, Long Island, New York.

I Mr. W. P. Carl, Jr., Dynamic Developments, Inc., Babylon, Long Island, New York.

1 EDO Corporation, College Point, Long Island, New York.

1 Mr. H. E. Brooke, Hydrodynamics Laboratory, Convair, San Diego 12, Califormia。

1 Miami Shipbuilding Corporation, 615 S. W. Second Avenue, Miami 36, Florida.

1 Baker Manufacturing Company, Evansville, Wisconsin.

1 Gibbs and $\mathrm{C}_{\mathrm{ox}}$, Inc., 21 West Street, New York 16, New York.

1 Dr. H. Reichardt, Max-Planck-Institut fuer Stroemungsforschung, Goettingem, Boettingerstrass 6/8, West Germany.

1 Director of Research, National Aeronautics and Space Administration, Lewis Research Center, 21000 Brookpark Road, Cleveland 35, Ohio.

Hydronautics, Inc., 200 Monroe Street, Rockville, Maryland, Attn:

1 - Mr。 Phillip Eisenberg

I - Mr. M. P. Tulin

1 Commanding Officer and Director, U. S. Naval Civil Engineering Laboratory, Port Hueneme, California, Attn: Code L54.

1 Micro-Tech Research Company, 629 Massachusetts Avenue, Cambridge, Massachusetts, Attn: Mr. Cohoon.

1 Professor J. E. Cermak, Department of Civil Engineering, Colorado State University, Fort Collins, Colorado.

1 Mr. Blaine Parkin, The Rand Corporation, 1700 Main Street, Santa Monica, California. 
1 Gleveland Pneumatic Industry, Inc., Advanced Systems Development Division, 1301 E. El Segundo Boulevard, El Segundo, California.

1 Mr. George H. Pedersen, Turbomachinery Division, Curtiss-Wright Corporation, Research Division, Quehanna, Pennsylvania.

$1 \quad$ Mr. Kenneth E. Hodge, Hydrodynamics Research, Lockheed Aircraft Corporation California Division, Burbank, California.

1 Dr. Byrne Perry, Department of Civil Engineering, Stanford University, Stanford, California.

1 Dr. J. Kotik, Technical Research Group Incorporated, 2 Aerial Way, Syosset, New York. 